\title{
Kinetic studies on organic degradation and its impacts on improving methane production during anaerobic digestion of food waste
}

\author{
Yangyang Li ${ }^{\mathrm{a}, \mathrm{b}}$, Yiying Jin ${ }^{\mathrm{a}, \mathrm{b},{ }^{*},}$, Hailong $\mathrm{Li}^{\mathrm{c}}$, Aiduan Borrion ${ }^{\mathrm{d}}$, Zhixin Yu ${ }^{\mathrm{e}}$ Jinhui $\mathrm{Li}^{\mathrm{a}}$, \\ a, School of Environment, Tsinghua University, Beijing 100084, China \\ b, Key Laboratory for Solid Waste Management and Environment Safety (Tsinghua University),
} Ministry of Education of China, Tsinghua University, Beijing 100084, China

c, Mälardalen University, School of Sustainable Development of Society and Technology, SE-721

23 Västerås, Sweden

d, Dept of Civil, Environ \& Geomatic Eng, University College London, London WC1E 6BT, UK

e, Department of Petroleum Engineering, University of Stavanger, N-4036 Stavanger, Norway

\begin{abstract}
Organics degradation is vital for food waste anaerobic digestion performance, however, the influence of organics degradation on biomethane production process has not been fully understood. This study aims to thoroughly investigate the organics degradation performance and identify the interaction between the reduction of organic components and methane yield based on the evaluation on 12 types of food waste. Five models (i.e. exponential, Fitzhugh, transference function, Cone and modified Gompertz models) were compared regarding the prediction of organic degradation and the results showed that the exponential model fit the experiments best, whereas kinetic parameters could not be commonly used for all situations. The exponential model was then used to study
\end{abstract}

\footnotetext{
* Corresponding author. Address: School of Environment, Tsinghua University, Beijing, China. Tel.: +8610 62794352; Fax: +861062797618.

E-mail address: jinyy@tsinghua.edu.cn.
} 
the impacts of organics reduction on the methane production and results revealed that the cumulative methane production $(385-627 \mathrm{~mL} / \mathrm{g}$ volatile solid) increased exponentially with the removal efficiency of volatile solids, lipids, and proteins for all feedstocks, whereas volatile solid reduction increased exponentially and linearly, respectively, with the removal efficiency of lipids and proteins. Additionally, protein degradation increased exponentially with the reduction efficiency of lipids. The experimental data and model simulation results suggested that higher methane production (530-548 $\mathrm{mL} / \mathrm{g}$ volatile solid) and removal efficiency of volatile solids (65.0-67.8\%), lipids (77.8-78.2\%), and proteins (54.7-58.2\%) could be achieved in a shorter digestion retention when carbohydrate content was higher than $47.6 \%$, protein content lower than $24.1 \%$, and lipid content lower than $28.3 \%$.

\section{Keywords}

Food waste; Anaerobic digestion; Organic composition; Methane; kinetics 


\section{Introduction}

Anaerobic digestion of food waste is attracting more and more attention worldwide for recovering energy and reducing greenhouse gas emissions [1,2]. There have been many studies focused on the effect of operating parameters on methane yields, such as operation mode (batch or continuous), temperature (mesophilic or thermophilic), moisture content (wet or dry), organic loading rate, presence or absence of co-substrates (co- or mono-digestion) and hydraulic retention time [3-6]. Furthermore, in order to increase digestion efficiency and improve the methane yield, anaerobic biodegradability of food waste in two-stage [7] and three-stage [8] anaerobic digesters have also been studied, and various pretreatment methods [6, 9, 10$]$ have been proposed. The energy ratio and economic feasibility were also conducted [9].

Meanwhile, to allow the prediction of kinetic parameters and to help elucidate the digestion process, some kinetic models have been proposed to describe the process of substrate degradation and biogas production. Simplified generalized models based on first order models have predominantly been employed for parameter estimation, improving the understanding of the biological process and aiding in predicting the behaviour of biological system when designing anaerobic system [11]. It was concluded that kinetic parameters, such as those of biogas production and methane yield, may vary when different models and substrates were used [12]. Li et al. [13] compared three kinetics models, including first-order kinetics, the transfer function model and the cone model for different livestock manures as feedstocks and with 
different substrate concentrations. The results showed that the cone model had better performance than the first-order and the transfer function models. Kafle and Kim [14] compared the modified Gompertz and first-order kinetics models and showed that, better fitting result was found for the modified Gompertz model. El-Mashad [15] observed that the Cone model best described the cumulative biogas production data, whereas the exponential model was the worst predictor of the experimental data. Moreover, due to the structural and numerical complexity, many models cannot be applied for automatic monitoring or robust simulation of different substrates and process conditions [16]. It is important to highlight that previous studies devoted to the kinetic parameters during digestion of food waste were simplified to focus on fitting the experimental data of biogas/methane production [10], and very few studies centred on the detailed kinetic degradation properties of organics in food waste (i.e. volatile solids, total solids, lipids and proteins) and their correlations during the anaerobic digestion of food waste. Additionally, food waste can present important differences as the composition can vary with factors such as food availability, seasonal variation and consumption patterns. For food waste, lipids are one of the main organic components and may have a bi-directional effect on digestion [17]. However, calculation of the hydrolysis constant using kinetic models from the previous study was only made for a combined fraction of carbohydrates and proteins, omitting the lipid fraction [18]. Moreover, Miron et al. [18] suggested that the hydrolysis constant value might not be a universal constant, as it is no more than a specific calculation for a given substrate 
under certain conditions. However, it could be noted that previous studies devoted to the kinetic parameters during digestion of food waste (including mono- and co-digestion) were confined to using collected food waste with limited composition ranges [19] and co-digestion with other organic waste (such as dairy manure [20] and sewage sludge [21]).

Therefore, there is a need to extend kinetic models to organics reduction and verify whether kinetic parameters meet this important assumption. Thus, it is necessary to make comparisons of these kinetics models (i.e. the exponential, Fitzhugh, Cone, transference function and modified Gompertz models), which were used to determine the methane production potential, maximum methane production rate and lag time for anaerobic digestion by fitting the measured methane yields [13, 16, 22-27], and find the appropriate one by model validation for parameter estimation. To further increase the digestion efficiency and improve the biomethane production, making the overall process more energy sustainable, the interaction of organics degradation and their impact on methane production should be studied.

The objectives of this paper are to investigate the degradation performance of organics (i.e. total solids, volatile solids, lipids, and proteins) and maximize the methane yield of food waste by optimizing organics degradation during food waste digestion. This work contributes to improvement the understanding of: a) the applicability and validation of five simplified and widely applied models for predicting biomethane production performance; and b) the correlation between the organics 
reduction in terms of volatile solids, proteins and lipids in food waste. Finally, the optimizations for enhancing biomethane production through the improvement of organic degradation were suggested.

\section{Materials and Methods}

\subsection{Food waste}

Food waste was collected from three different canteens. Impurities, such as big bones, plastics, and metals were manually removed from the food waste. Samples collected from the same canteen were mixed with a kitchen blender to ensure uniform and representative experimental materials. The mixed samples were then macerated to an average size of 1-2 $\mathrm{mm}$. All samples were stored at $4{ }^{\circ} \mathrm{C}$ in a refrigerator for the subsequent experiments. The basic compositions and characteristics of the three kinds of food waste used in this experiment are listed in Table 1a.

The ranges of variation of food waste compositions were obtained from a literature review and measurements of samples from 5 typical Chinese cities (e.g. Beijing in North China; Jiaxing in Zhejiang province, East China; Xining in Qinghai province, Northwest China; Qingdao in Shandong province, coastal East China and Guiyang in Guizhou province, South China). A total of 12 different types of food waste with different carbohydrate: protein: lipid ratios were then formed by mixing the three kinds of food waste samples with different ratios, as shown in Table $\mathbf{1 b}$.

The $\mathrm{pH}$ was measured using a $\mathrm{pH}$ meter (FE 20, Mettler, Switzerland). Total solids, volatile solids and concentrations of total ammonia nitrogen were determined 
according to the standard methods from the American Public Health Association [28]. The concentration of carbohydrates was analysed according to official methods [29]. The concentrations of proteins and lipids were determined according to the Kjeldahl method and using a Soxhlet device extracted by petroleum ether, respectively [30, 31]. Methane production was determined using real-time methane yield recording systems (automatic methane potential test system II). The contents of $\mathrm{C}, \mathrm{H}$ and $\mathrm{N}$ were analysed by CHN Elemental Analysers (CE-440 elemental analyser (EAI Co. Ltd)) and O content was investigated with a PerkinElmer 2400 analyser.

Table 1a. Compositions and characteristics of the three food waste samples.

\begin{tabular}{llll}
\hline Parameters & food waste- 1 & food waste- & food waste-3 \\
\hline $\mathrm{pH}$ & $4.5 \pm 0.2$ & $5.2 \pm 0.0$ & $5.0 \pm 0.2$ \\
Total solid (\%) & $19.1 \pm 1.1$ & $26.2 \pm 0.4$ & $12.7 \pm 0.7$ \\
Volatile solid (\% total solid) & $93.2 \pm 1.4$ & $94.8 \pm 0.5$ & $95.4 \pm 1.2$ \\
Carbohydrate (\%) & $11.8 \pm 0.4$ & $10.3 \pm 0.3$ & $36 \pm 2.5$ \\
Protein (\%) & $2.5 \pm 0.2$ & $6.3 \pm 0.5$ & $41.5 \pm 1.8$ \\
Lipid (\%) & $3.5 \pm 0.1$ & $8.2 \pm 0.2$ & $18.5 \pm 0.4$ \\
$\mathrm{C}(\%$ total solid) & $46.1 \pm 1.6$ & $52.2 \pm 1.4$ & $51.5 \pm 0.6$ \\
$\mathrm{H}(\%$ total solid) & $7.0 \pm 0.2$ & $5.4 \pm 0.6$ & $7.5 \pm 0.3$ \\
O (\% total solid) & $37.8 \pm 1.6$ & $32.0 \pm 0.4$ & $32.8 \pm 0.7$ \\
$\mathrm{~N}(\%$ total solid) & $3.2 \pm 0.4$ & $4.0 \pm 0.1$ & $5.3 \pm 0.2$ \\
\hline
\end{tabular}




\section{Table $1 b$.}

Characteristics of the 12 feedstock compositions for anaerobic digestion runs (M 1-M 12).

\begin{tabular}{|c|c|c|c|c|c|c|c|c|c|c|c|c|}
\hline Parameters & M 1 & M 2 & M 3 & M 4 & M 5 & M 6 & M 7 & M 8 & M 9 & M 10 & M 11 & M 12 \\
\hline Total solid (\%) & 16.7 & 19.1 & 17.2 & 20.5 & 19.7 & 19.6 & 20.0 & 20.8 & 19.2 & 20.9 & 24.7 & 18.7 \\
\hline $\begin{array}{l}\text { Volatile solid (\% } \\
\text { total solid) }\end{array}$ & 98.2 & 97.0 & 97.2 & 96.5 & 96.7 & 96.5 & 96.3 & 95.9 & 96.1 & 95.8 & 95.2 & 95.3 \\
\hline $\begin{array}{l}\text { Carbohydrate (\% } \\
\text { volatile solid) }\end{array}$ & 73.3 & 58.4 & 56.3 & 55.4 & 53.0 & 49.4 & 47.6 & 41.4 & 41.3 & 38.4 & 34.3 & 17.1 \\
\hline $\begin{array}{l}\text { Protein (\% volatile } \\
\text { solid) }\end{array}$ & 20.7 & 21.4 & 26.7 & 18.0 & 22.4 & 24.1 & 24.1 & 25.3 & 28.4 & 26.3 & 22.4 & 44.1 \\
\hline $\begin{array}{l}\text { Lipid (\% volatile } \\
\text { solid) }\end{array}$ & 6.0 & 20.2 & 17.1 & 26.6 & 24.6 & 26.4 & 28.3 & 33.3 & 30.3 & 35.3 & 43.3 & 38.8 \\
\hline $\mathrm{C}(\%$ total solid $)$ & 43.0 & 45.5 & 45.6 & 46.9 & 46.5 & 47.1 & 47.5 & 48.8 & 48.4 & 49.4 & 51.5 & 51.5 \\
\hline $\mathrm{H}(\%$ total solid $)$ & 6.5 & 6.8 & 6.8 & 7.1 & 7.0 & 7.0 & 7.1 & 7.3 & 7.2 & 7.4 & 7.7 & 7.5 \\
\hline N (\%total solid) & 2.5 & 2.6 & 3.4 & 2.6 & 2.8 & 3.1 & 3.1 & 3.3 & 3.8 & 3.5 & 2.9 & 5.3 \\
\hline $\mathrm{C} / \mathrm{N}$ & 17.5 & 17.7 & 13.4 & 17.8 & 16.8 & 15.4 & 15.5 & 14.7 & 12.7 & 14.0 & 18.1 & 9.7 \\
\hline $\begin{array}{l}\text { Carbohydrate: } \\
\text { protein: lipid }\end{array}$ & $12.2: 3.4: 1$ & $2.9: 1.1: 1$ & 3.3:1.6:1 & $2.1: 0.7: 1$ & $2.2: 0.9: 1$ & 1.9:0.9:1 & $1.7: 0.9: 1$ & 1.2:0.8:1 & 1.4:0.9:1 & $1.1: 0.7: 1$ & $0.8: 0.5: 1$ & $0.4: 1.1: 1$ \\
\hline $\begin{array}{l}\text { Experimental } \\
\text { methane yields }(\mathrm{mL}\end{array}$ & 384.6 & 508.8 & 460.5 & 536.2 & 536.2 & 530.3 & 548.1 & 564.6 & 541.1 & 545.3 & 626.9 & 574.4 \\
\hline
\end{tabular}




\section{$\left.\mathrm{CH}_{4} / \mathrm{g} \mathrm{VS}^{\mathrm{a}}\right)$}

Theoretical methane yield $\left(\mathrm{mL} \mathrm{CH}_{4} / \mathrm{g}\right.$ 435.1 528.9

514.6

575.5

558.9

573.5

585.9

621.2

604.8

636.0

686.9

684.1

Experimental yield/

Theoretical yield

88.4

96.2

89.5

93.2

95.9

92.5

93.5

90.9

89.5

85.7

91.30

84.0

${ }^{a}$ : Volatile solid. ${ }^{b}$ : Theoretical methane potential based on component composition (fat, protein and carbohydrate) [32]. 


\subsection{Anaerobic digestion}

Batch digestion tests were conducted at $37{ }^{\circ} \mathrm{C}$ by using an automatic methane potential test system II developed by Bioprocess Control (Lund, Sweden). The feed and inoculums were placed into bottles with a feed to inoculums ratio of 1:2 on a volatile solid basis. Seed sludge was obtained from a steady-operation digester $\left(37^{\circ} \mathrm{C}\right)$ in a food waste treatment plant in Beijing, China. After a two-day gravity sedimentation period, the inoculum was passed through a $2 \mathrm{~mm}$ sieve to remove any large particles or grit to arrive at total solid and volatile solid contents of $3.65 \%$ and $2.42 \%$, respectively, whereas the $\mathrm{pH}$ value was 7.34 before mixing with the food waste. The upper space of each reactor was flushed with nitrogen for at least $1 \mathrm{~min}$ to guarantee anaerobic conditions before the reactor was sealed. Then, all of the reactors were placed in the digestion system water bath and maintained at a mesophilic temperature $\left(37^{\circ} \mathrm{C}\right)$. For each experimental run, three control digesters were operated. Simultaneously, two blank digesters containing only inoculums were incubated to correct for any biogas yield from the inoculums.

To achieve accurate model predictions, it is important to maintain an anaerobic environment during the entire digestion process and collect samples at appropriate times (e.g., inhibition stage, recovery stage, finial stage, etc.). Two sets of digestion systems were used in this study, and the real-time methane productivity was measured by a system containing $500-\mathrm{mL}$ glass bottles, whereas a system with $2 \mathrm{~L}$ glass bottles was used for sample collection and indicator detection. All of the bottles in both systems were fed from the same kinds of substrates and had the same feed to 
inoculums ratio. The later set was started two days after the first one to immediately collect samples based on the methane yield patterns from the first set. The methane yield of 12 types of food waste during the digestion process was evaluated - defined as the total volume of methane produced per amount of food waste initially added (i.e. $\mathrm{mL} \mathrm{CH}_{4} / \mathrm{g}$ volatile solid added).

\subsection{Kinetics models}

During the 30 days allotted for the digestion process, the concentrations of total solids, volatile solids, proteins, and lipids were tested continuously. Five models were used to determine the kinetic parameters with the results described in the following sections.

The different kinetics models including the exponential, Fitzhugh, Cone, transference function and modified Gompertz models were used to determine the methane production potential, maximum methane production rate and lag time for anaerobic digestion by fitting the measured methane yields [13, 16, 22-27]. In this study, the five models were evaluated for their performance and kinetics parameters including the maximum degradation potential, maximum degradation rate and lag time for organics degradation during digestion process via fitting the reduction of the total solids, volatile solids, lipids, and proteins:

$$
\begin{aligned}
& \text { Exponential kinetics: } B=B_{0} \times[1-\exp (-k \mathrm{t})] \\
& \text { Fitzhugh model: } \\
& \text { Cone model: }
\end{aligned}
$$

Transference function: $B=B_{0} \times\left\{1-\exp \left[-\mu_{\mathrm{m}} \times(t-\lambda) / \mathrm{B}_{0}\right]\right\}$ 
Modified Gompertz model: $B=B_{0} \times \exp \left\{-\exp \left[e \times \mu_{\mathrm{m}} \times(\lambda-t) / \mathrm{B}_{0}+1\right]\right\}$

where $B$ represents the cumulative organics reduction (e.g., total solid reduction, volatile solid reduction, lipid reduction and protein reduction) for a digestion time $t$ $(\%), B_{0}$ is the ultimate organics reduction (e.g., total solid reduction, volatile solid reduction, lipid reduction and protein reduction) of the samples (\%), $k$ is the first-order reduction rate constant for the total solid reduction, volatile solid reduction, lipid reduction and protein reduction $\left(\mathrm{d}^{-1}\right), \mu_{\mathrm{m}}$ is the maximum organics reduction rate for the total solid reduction, volatile solid reduction, lipid reduction and protein reduction, $\lambda$ is the lag time (d), $t$ is time (d), and $e$ is the base of a natural logarithm (2.7183).

The correlation coefficients $\left(R^{2}\right)$, Root Mean Square Error (RMSE) and Akaike's Information Criterion (AIC) were indicators used for model evaluation:

(1) $R^{2}$, also known as the goodness-of-fit-index, was determined using the OriginPro 8.0 software supplied by Origin Lab Corp.

(2) RMSE is interpreted as the standard deviation between the predicted and measured values with a lower RMSE indicating a better fit:

$$
\operatorname{RMSE}=\sqrt{\sum_{\mathrm{i}=1}^{\mathrm{n}} \frac{\left(P V_{\mathrm{i}}-M V_{\mathrm{i}}\right)^{2}}{n}}
$$

where $P V_{\mathrm{i}}$ is the predicted value of organics reduction, $M V_{\mathrm{i}}$ is the measured value of organics reduction, and $n$ is number of measurements.

(3) AIC is an alternative method used for comparing models and determining which model is more likely to be correct and quantifies how much more likely using information theory. A second-order (corrected) AIC $\left(\mathrm{AIC}_{\mathrm{c}}\right)$ can be positive or 
negative, and it is more likely to be correct for models with a lower $\mathrm{AIC}_{\mathrm{c}}$ value than for models with higher ones [33]:

$\mathrm{AIC}_{\mathrm{c}}=N \ln (S S / N)+2 K+2 K(K+1) /(N-K-1)$,

where $N$ is the number of data points, $K$ is the number of parameters fit by the regression plus one (because regression is estimating the sum-of-squares as well as the parameter values), and $S S$ is the sum of the square of the vertical distances for the points from the curve.

\subsection{Statistical analysis}

\subsubsection{Second-order polynomial model analysis}

The response surface methodology was used to describe the relationship between the responses and independent variables. The functional relationships between the responses $(M)$ and the set of factors $(X$ and $Y$ ) were described by estimating the coefficients of the following second-order polynomial model based on the experimental data:

$$
M=M_{0}+a X+b Y+c X^{2}+d Y^{2}+f X Y
$$

where $M$ is the predicted response, $M_{0}$ is a constant, $X$ and $Y$ refer to the organics reduction (e.g., the volatile solid reduction, lipid reduction and protein reduction), $a$ and $b$ are linear coefficients, $c$ and $d$ are quadratic coefficients, and $f$ is the interaction coefficient.

\subsubsection{ANOVA}

The results and the coefficients of the quadratic equation were analysed using an ANOVA $(p<0.05)$ via the $\mathrm{R}$ software 3.3.2 package (Table S1). 


\section{Results and Discussion}

3.1. Food waste characteristics and process parameters

The performance of anaerobic biodegradability for 12 substrates was evaluated using batch tests. The total solid and volatile solid content in the 12 food waste samples ranged from $16.7 \%$ to $24.7 \%$ (wet basis) and $95.2 \%$ to $98.2 \%$ (dry basis), respectively (Table S2). Additionally, the organic composition in the feedstock on a volatile solid basis was: lipids from $6.1 \%$ to $45.5 \%$, proteins from $18.6 \%$ to $46.3 \%$, and carbohydrates from $18.0 \%$ to $74.7 \%$ - indicating significant variations in the volatile solid fraction. The initial concentration of the total solid in the digester varied from $6.75 \%$ to $7.30 \%$, and it could be concluded that all these digestion systems were classified as wet fermentation processes.

The retention time for the whole digestion lasted for 30 days, and the time needed for $90 \%$ methane production was less than 18 days, indicating that the organic solid remaining in the final period of digestion would be almost more refractory organic compounds instead of more readily degraded organics (such as cellulose), which were degraded slowly by bacteria [4, 34]. Due to differences in the organics compositions in terms of carbohydrates, proteins, and lipids, variations in the anaerobic digestion parameters (including $\mathrm{pH}$, organics reduction, volatile fatty acid concentration, and total ammonia nitrogen concentration) were observed during the digestion process. For example, the initial $\mathrm{pH}$ of 12 digesters was appropriately 7.79, and the final $\mathrm{pH}$ ranged from 7.79 to 7.99 after 30 days of anaerobic digestion. The $\mathrm{pH}$ in all digesters was higher than 7.45 during the entire digestion process, which 
are all above the ideal $\mathrm{pH}$ range for anaerobic digestion (i.e. 4.0-8.5 for fermentative bacteria and 6.5-7.2 for methanogens [35]). Both theoretical methane potentials and measured methane yields (in laboratory batch tests) for the 12 tested food waste samples are shown in Table $1 \mathrm{~b}$. The theoretical methane yields varied due to the differences in the organics compositions, ranging from 435 to $687 \mathrm{~mL} / \mathrm{g}$ volatile solid, while the experimental values varied from 385 to $627 \mathrm{~mL} / \mathrm{g}$ volatile solid. The methane yield fell within the range of $200-570$ and 300-1100 summarized by Braguglia et al. (2018) [36] and Xu et al. (2018) [37], respectively. The ratios of measured methane yield to theoretical potentials varied from $84 \%$ to $96 \%$. For the ratios, previous research reported different results, such as $81.51 \%$ by Zhou et al. (2014) [38] and $74.8 \%$ by Li et al. (2013) [39]. The variations of above parameters (e.g. methane yield, ratios of measured methane yield to theoretical potentials) could be attributed to factors such as the quantity and quality of the inoculums, batch digestion test parameters (e.g. digestion temperatures, substrate to inoculum ratios) and substrate characteristics (e.g. organic ingredients, volatile solid content). In addition, the volatile solid reduction ranged from $66.6 \%$ to $70.1 \%$. All these results indicated that the operational conditions were good and the digestion was successful.

\subsection{Organics degradation performance during digestion process}

\subsubsection{Characteristics of total solid degradation}

For the exponential, Fitzhugh and transference function models, similar ultimate total solid reduction $\left(B_{0}\right)$ were estimated for all 12 substrates, whereas the results from the modified Gompertz model are $0.20 \%-3.75 \%$ lower. Although the highest 
regression of coefficients in all cases came using the Cone model (above 0.98), there was no overall agreement on $B_{0}$ between the model and the experimental data (Table 2).

Higher reduction rate constants $(k)$ are estimated by exponential models compared with the Fitzhugh model. Organic compositions in food waste have a synergetic influence on the kinetic parameters, and the variations of $k$ with the change of organic compositions are similar for the above models, indicating higher values of higher carbohydrate concentrations and lower lipid concentrations in substrates. Carbohydrate exhibit higher degradation rates, whereas lower rates are achieved for lipids compared with proteins [40]. Therefore, the degradation of these two organics has a major influence on the $k$, whereas little influence is seen for variations of protein concentrations in the substrates. The details of the biodegradation rates for lipid and protein are discussed in the following sections.

The lag time $(\lambda)$ estimated by the transference model may be negligible in all the cases, which indicates that the soluble material in the liquid phase of the substrates was quickly consumed by the anaerobic microorganisms. Food waste is characterized as having high degrees of readily degradable materials and the digestibility is increased further by the pretreatment, such as sanitation processes and thermal pretreatment. Thus, the biogas is produced immediately from these soluble organics after the initiation of the batch tests. Similar results were obtained by Konrad et al [41] in biodegradability batch bests at the same temperature when food waste was co-digested in municipal wastewater treatment plants. Donoso-Bravo et al. 
[22] reported that the lag time may be negligible in batch experiments at $35{ }^{\circ} \mathrm{C}$ when sewage sludge was processed by thermal and ultrasound pretreatments prior to subsequent digestion. The $\lambda$ values estimated by the modified Gompertz model varied from $0.05 \mathrm{~d}$ to $0.52 \mathrm{~d}$ for all of the substrates, indicating a short lag phase for the biodegradation of the total solid. El-Mashad [15] reported a longer lag phase for the modified Gompertz model in bovine serum albumin digestion and a slower reduction rate for protein than for starch. However, similar results could not be concluded on the studied conditions - indicating no significant variations in the lag time at higher protein contents. As an example, the highest and lowest $\lambda$ values were achieved at $0.52 \mathrm{~d}$ and $0.05 \mathrm{~d}$ when the protein content in the substrates were $17.99 \%$ and $26.27 \%$ (volatile solid basis), respectively. In this study, the varied lag time was due to variations in the organic compositions in terms of the carbohydrates, proteins, and lipids, which could show a synergetic influence on the lag time during total solid digestion. Small variations in the protein content in the substrates have an obvious influence on the $\mu_{\max }$ predicted by both models, whereas no significant variations are seen for the carbohydrates and lipids.

In addition, the maximum methane production rate $\left(\mu_{\max }\right)$ estimated using the Transference and modified Gompertz models showed similar variation tendencies for all of the substrates with different organic compositions, and higher $\mu_{\max }$ values may be achieved for the Transference model. The correlations in the predicted $\mu_{\max }$ values between the Transference $\left(\mu_{\max }-\mathrm{T}\right)$ and modified Gompertz models $\left(\mu_{\max }-\mathrm{G}\right)$ may be described by a linear model. The regression coefficients are shown in the 
following equation:

$$
\mu_{\max }-\mathrm{G}=0.527 \mu_{\max }-\mathrm{T}+0.137 \quad\left(R^{2}=0.982\right) .
$$

The statistical indicators $\left(R^{2}, \mathrm{RMSE}\right.$, and $\left.\mathrm{AIC}_{\mathrm{c}}\right)$ for the first four models for the total solid reduction are shown in Table 2. The highest $R^{2}$ values were obtained using the exponential model $(0.9275-0.9957)$ with only two exceptions, in which exponential model had almost the same values as the modified Gompertz model. The highest RMSE values were obtained for modified Gompertz model, whereas those for the other three models had similarly low RMSE values $(0.0098-0.0411)$ with one exception in which modified Gompertz model possessed the lowest RMSE values. The lowest $\mathrm{AIC}_{\mathrm{c}}$ were obtained using the exponential model (-211 - -177), followed by the Fitzhugh and Transference models, which exhibited similar values. The modified Gompertz model exhibited the highest $\mathrm{AIC}_{\mathrm{c}}(-208--142)$. The lowest RMSE and the lowest $\mathrm{AIC}_{\mathrm{c}}$ between the predicted and measured total solid reduction indicated that the exponential model is the best model for fitting the total solid reduction data which was also strongly supported by the highest $R^{2}$ values. However, the modified Gompertz model had the overall lowest $R^{2}$ values and highest RMSE and $\mathrm{AIC}_{\mathrm{c}}$, indicating poor fitting, whereas the Cone model had the worst fitting in terms of predicting the total solid reduction efficiency. 
Table 2. Estimated parameters for the five models and the $R^{2}, \mathrm{RMSE}$ and $\mathrm{AIC}_{\mathrm{c}}$ of the different models based on the total solid reduction.

\begin{tabular}{|c|c|c|c|c|c|c|c|c|c|c|c|c|c|}
\hline Models & Parameters & M1 & M2 & M3 & M4 & M5 & M6 & M7 & M8 & M9 & M10 & M11 & M12 \\
\hline \multirow{3}{*}{ Exponential } & $k$ & 2.27 & 1.03 & 3.63 & 0.55 & 1.27 & 2.91 & 1.38 & 1.12 & 2.32 & 0.67 & 1.61 & 1.56 \\
\hline & $R^{2}$ & 0.9852 & 0.9897 & 0.9957 & 0.9529 & 0.9896 & 0.9659 & 0.9275 & 0.9486 & 0.9664 & 0.9743 & 0.9558 & 0.9770 \\
\hline & RMSE & 0.02 & 0.02 & 0.01 & 0.04 & 0.01 & 0.03 & 0.04 & 0.03 & 0.03 & 0.02 & 0.03 & 0.02 \\
\hline \multirow{4}{*}{ Fitzhugh } & $B_{0}$ & 54.63 & 56.70 & 55.11 & 56.07 & 53.14 & 53.91 & 54.91 & 54.74 & 51.61 & 53.93 & 51.47 & 51.15 \\
\hline & $k$ & 1.51 & 1.02 & 1.90 & 0.74 & 1.13 & 1.71 & 1.17 & 1.06 & 1.52 & 0.82 & 1.27 & 1.25 \\
\hline & $n$ & 1.51 & 1.02 & 1.90 & 0.74 & 1.13 & 1.71 & 1.17 & 1.06 & 1.52 & 0.82 & 1.27 & 1.25 \\
\hline & $R^{2}$ & 0.9833 & 0.9884 & 0.9952 & 0.9470 & 0.9883 & 0.9616 & 0.9184 & 0.9422 & 0.9622 & 0.9711 & 0.9502 & 0.9741 \\
\hline \multirow{4}{*}{ Transference } & $B_{0}$ & 54.63 & 56.71 & 55.11 & 55.98 & 53.14 & 53.91 & 54.94 & 54.77 & 51.61 & 53.95 & 51.47 & 51.15 \\
\hline & $\mu_{\mathrm{m}}$ & 1.24 & 0.58 & 2.00 & 0.32 & 0.67 & 1.57 & 0.75 & 0.61 & 1.20 & 0.36 & 0.83 & 0.79 \\
\hline & $\lambda$ & 0.00 & -0.01 & 0.00 & 0.07 & 0.00 & 0.00 & -0.01 & -0.01 & 0.00 & -0.01 & 0.00 & 0.00 \\
\hline & $R^{2}$ & 0.9833 & 0.9884 & 0.9952 & 0.9489 & 0.9883 & 0.9616 & 0.9186 & 0.9424 & 0.9622 & 0.9712 & 0.9502 & 0.9741 \\
\hline
\end{tabular}




\begin{tabular}{|c|c|c|c|c|c|c|c|c|c|c|c|c|c|}
\hline & RMSE & 0.02 & 0.02 & 0.01 & 0.04 & 0.01 & 0.03 & 0.04 & 0.03 & 0.03 & 0.02 & 0.03 & 0.02 \\
\hline \multirow{5}{*}{ Gompertz } & $B_{0}$ & 54.52 & 55.87 & 55.10 & 53.88 & 52.61 & 53.85 & 54.09 & 55.00 & 51.48 & 52.57 & 51.14 & 51.67 \\
\hline & $\mu_{\mathrm{m}}$ & 0.81 & 0.43 & 1.16 & 0.33 & 0.49 & 0.97 & 0.61 & 0.44 & 0.78 & 0.25 & 0.59 & 0.56 \\
\hline & $\lambda$ & 0.17 & 0.11 & 0.18 & 0.52 & 0.14 & 0.17 & 0.12 & 0.08 & 0.17 & 0.05 & 0.16 & 0.15 \\
\hline & RMSE & 0.02 & 0.02 & 0.01 & 0.03 & 0.02 & 0.03 & 0.04 & 0.04 & 0.03 & 0.03 & 0.03 & 0.02 \\
\hline & $\mathrm{AIC}_{\mathrm{c}}$ & -180 & -171 & -208 & -165 & -178 & -163 & -142 & -152 & -165 & -157 & -157 & -142 \\
\hline \multirow{4}{*}{ Cone } & $B_{0}$ & 179.73 & 58.69 & 55.24 & 54.79 & 55.27 & 184.79 & 68.88 & 70.72 & 249.43 & 55.94 & 101.31 & 57.59 \\
\hline & $k$ & 0.00 & 1.59 & 7.49 & 0.74 & 2.28 & 0.00 & 4.08 & 2.12 & 0.00 & 0.96 & 0.14 & 6.81 \\
\hline & RMSE & 0.01 & 0.01 & 0.01 & 0.02 & 0.01 & 0.02 & 0.02 & 0.01 & 0.01 & 0.02 & 0.01 & 0.01 \\
\hline & $\mathrm{AIC}_{\mathrm{c}}$ & -234 & -222 & -209 & -173 & -227 & -187 & -173 & -204 & -212 & -180 & -191 & -220 \\
\hline
\end{tabular}




\subsubsection{Characteristics of volatile solid degradation}

As shown in Table 3, for the exponential, transference, and Fitzhugh models, similar volatile solid reductions $\left(B_{0}\right)$ are achieved ranging from $60.74 \%$ to $66.40 \%$, whereas those estimated by the modified Gompertz model (varied from $60.64 \%$ to $65.22 \%)$ are lower. For the Cone model, the predicted $B_{0}$ varied from those obtained by the other four models, which also showed no agreement with the experimental data.

Higher reduction rate constants $(k)$ were estimated for the exponential model compared to the Fitzhugh model, which showed similar tendencies. The correlations of the predicted $k$ estimated between the exponential $\left(k_{\mathrm{E}}\right)$ and Fitzhugh models $\left(k_{\mathrm{F}}\right)$ could be described by a linear model and the regression coefficients are shown by:

$$
k_{\mathrm{F}}=0.396 k_{\mathrm{E}}+0.590\left(R^{2}=0.962\right) .
$$

The lag time $(\lambda)$ estimated for the Transference model varied from $-0.03 \mathrm{~d}$ to 0.08 $\mathrm{d}$, indicating an instant biodegradation of the organics in the food waste. The negative $\lambda$ values may be due to the parameter estimation errors, which could be considered as a no lag phase. The lag phase estimated using the modified Gompertz model ranged from $0.09 \mathrm{~d}$ to $0.49 \mathrm{~d}$, which was longer than with the transference model. The $\lambda$ value estimated for the transference and modified Gompertz models indicated a very quick consumption of the organics in the liquid phase and the solubilization of organics from the solid phase. Similar results were obtained by Donoso-Bravo et al [22].

Longer lag times for the volatile solids estimated via the modified Gompertz 
model were achieved compared with the total solid. This may be due to the following. As shown in Table 1b, volatile solids accounted for $95.2 \%-98.2 \%$ in the 12 food waste samples (total solid basis). Additionally, soluble organics and those ready to be solubilized in total or volatile solids are easily released into the liquid phase, which are available for use by microorganisms for biomethane conversion [42]. For this reason, a higher $\mu_{\max }$ value for volatile solids is estimated for the transference and modified Gompertz models is observed compared to the total solids.

For $\mu_{\mathrm{m}}$, higher values were predicted by the transference model compared to the modified Gompertz model. The lag time for the volatile solid degradation estimated from the transference model is negligible compared with the modified Gompertz model. Thus, the solubilization rates for the volatile solids obtained using the transference model is higher compared with the results estimated for the modified Gompertz model. The correlations for the predicted $\mu_{\max }$ values between the transference $\left(\mu_{\max }-\mathrm{T}\right)$ and modified Gompertz models $\left(\mu_{\max }-\mathrm{G}\right)$ may be described by a linear model and the regression coefficients are shown by:

$$
\mu_{\max }-\mathrm{G}=0.586 \mu_{\max }-\mathrm{T}+0.125\left(R^{2}=0.969\right) .
$$

In addition, the volatile solids contain three main organic components:

carbohydrates, proteins, and lipids. Thus, the synergetic effect of the bioavailability of the organic matters may be attributed to variations in the kinetic parameters for volatile solid reduction. Therefore, in the following sections, the degradation of the proteins and lipids is discussed. 
The statistical indicators $\left(R^{2}, \mathrm{RMSE}\right.$, and $\left.\mathrm{AIC}_{\mathrm{c}}\right)$ for the first four models for the volatile solid reductions are shown in Table 3. According to the predicted volatile solid reduction during digestion derived from the first four proposed models, the highest $R^{2}$ values were observed from the exponential model, followed by the Fitzhugh and transference models. Both the $R^{2}$ and RMSE values calculated by the Fitzhugh and transference models are similar. The lowest $\mathrm{AIC}_{\mathrm{c}}$ values were obtained by the exponential model (-155 - -103), followed by the transference model, with only four exceptions in which transference model exhibited the same low values as the exponential model. The modified Gompertz model exhibited the lowest $R^{2}$ value, but the highest RMSE and $\mathrm{AIC}_{\mathrm{c}}$ values occurred for the predicted and measured volatile solid reductions.

Therefore, the exponential model is best for fitting the volatile solid reduction data and the modified Gompertz model is not as accurate for data fitting, whereas the Cone model should not be used for volatile solid reduction prediction. 
Table 3. Estimated parameters for the five models and the $R^{2}, \mathrm{RMSE}$ and $\mathrm{AIC}_{\mathrm{c}}$ for the different models based on volatile solid reduction.

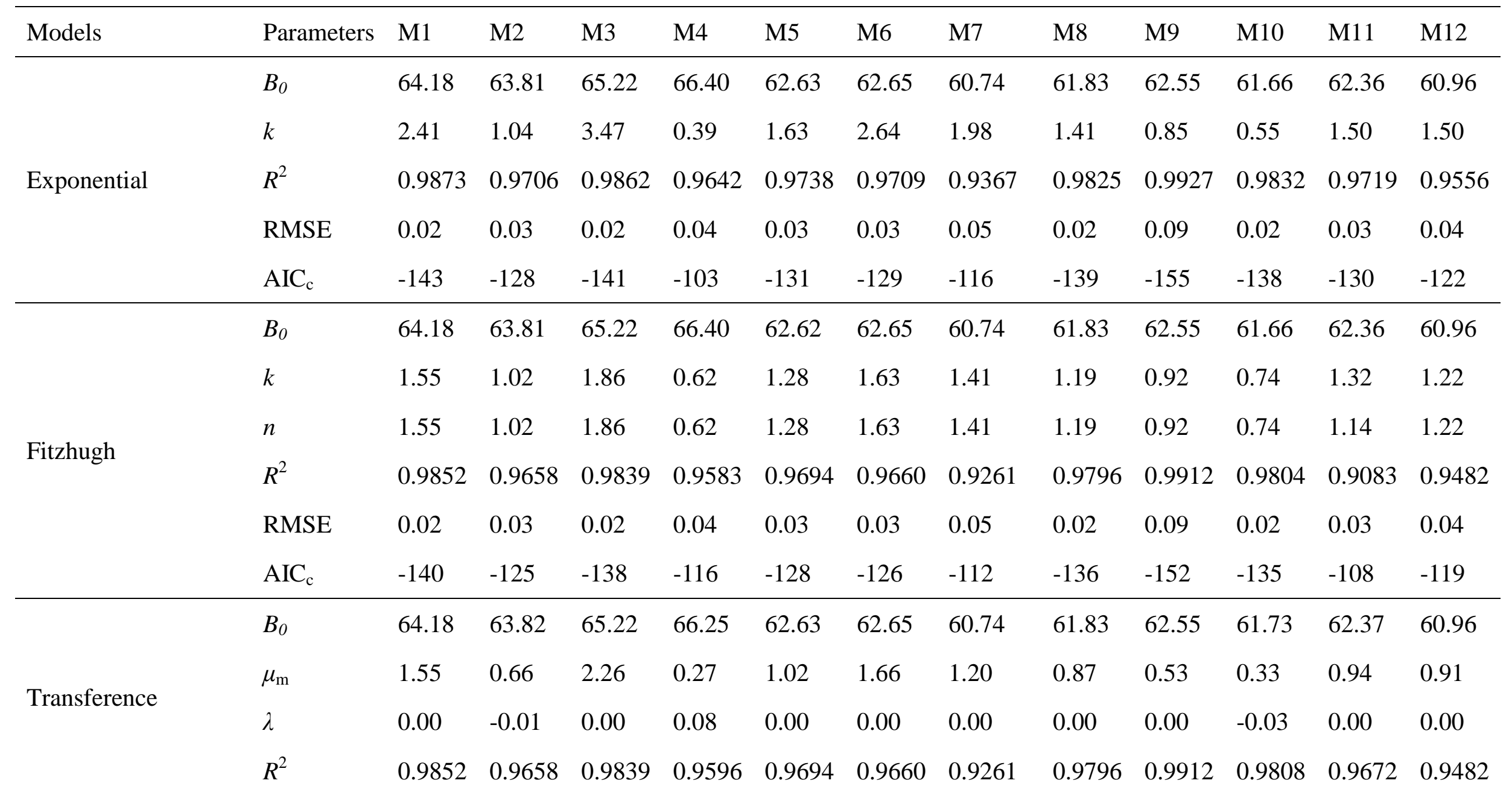




\begin{tabular}{|c|c|c|c|c|c|c|c|c|c|c|c|c|c|}
\hline & RMSE & 0.02 & 0.03 & 0.02 & 0.04 & 0.03 & 0.03 & 0.05 & 0.02 & 0.09 & 0.02 & 0.03 & 0.04 \\
\hline & $\mathrm{AIC}_{\mathrm{c}}$ & -140 & -125 & -151 & -116 & -128 & -147 & -140 & -136 & -152 & -135 & -127 & -119 \\
\hline \multirow{6}{*}{ Gompertz } & $B_{0}$ & 64.16 & 63.19 & 65.22 & 64.07 & 62.47 & 62.63 & 60.64 & 61.62 & 62.36 & 60.03 & 62.19 & 60.79 \\
\hline & $\mu_{\mathrm{m}}$ & 1.05 & 0.57 & 1.38 & 0.22 & 0.77 & 1.08 & 0.86 & 0.69 & 0.33 & 0.27 & 0.73 & 0.71 \\
\hline & $\lambda$ & 0.24 & 0.21 & 0.22 & 0.32 & 0.23 & 0.23 & 0.22 & 0.23 & 0.49 & 0.09 & 0.24 & 0.24 \\
\hline & $R^{2}$ & 0.9851 & 0.9567 & 0.9839 & 0.9628 & 0.9675 & 0.9659 & 0.9251 & 0.9769 & 0.9902 & 0.9576 & 0.9652 & 0.9462 \\
\hline & RMSE & 0.02 & 0.04 & 0.02 & 0.04 & 0.03 & 0.03 & 0.05 & 0.03 & 0.15 & 0.04 & 0.03 & 0.04 \\
\hline & $\mathrm{AIC}_{\mathrm{c}}$ & -121 & -120 & -138 & -118 & -127 & -126 & -112 & -133 & -150 & -118 & -125 & -118 \\
\hline \multirow{6}{*}{ Cone } & $B_{0}$ & 229.37 & 73.57 & 156.21 & 66.66 & 83.12 & 271.92 & 1229.77 & 68.48 & 64.73 & 65.51 & 82.44 & 454.47 \\
\hline & $k$ & 0.00 & 1.80 & 0.00 & 0.56 & 5.16 & 0.00 & 0.00 & 3.95 & 5.01 & 0.82 & 3.71 & 0.00 \\
\hline & $n$ & 0.06 & 0.64 & 0.05 & 1.90 & 0.28 & 0.06 & 0.09 & 0.61 & 0.81 & 1.19 & 0.31 & 0.11 \\
\hline & $R^{2}$ & 0.9955 & 0.9963 & 0.9921 & 0.9783 & 0.9971 & 0.9898 & 0.9841 & 0.9964 & 0.9933 & 0.9929 & 0.9965 & 0.9944 \\
\hline & RMSE & 0.01 & 0.01 & 0.02 & 0.03 & 0.01 & 0.02 & 0.02 & 0.01 & 0.04 & 0.01 & 0.01 & 0.01 \\
\hline & $\mathrm{AIC}_{\mathrm{c}}$ & -162 & -165 & -151 & -128 & -170 & -147 & -140 & -167 & -136 & -153 & -167 & -159 \\
\hline
\end{tabular}




\subsubsection{Characteristics of lipid degradation}

Table 4 shows that the Cone model failed to predict the kinetics parameters during simulation of the experiment data regarding lipid reduction. The ultimate lipid reductions $\left(B_{0}\right)$ estimated for the exponential and Fitzhugh models were almost identical. The $B_{0}$ value for sample M1 is approximately $293 \%$, compared with $139.85 \%$ and $37.66 \%$ for the transference and modified Gompertz models, respectively, indicating it was not accurate enough to predict the results from the first four models. The higher $B_{0}$ value was achieved for substrates with higher lipid contents and lower carbohydrate contents. For the other 11 types of substrates, the $B_{0}$ value varied from approximately $59 \%$ to $79 \%$. Due to the inaccurate prediction of $B_{0}$ for sample M1 from the first four models, only the kinetics parameters (e.g., $k, \mu_{\mathrm{m}}, \lambda$ ) for the other 11 types of substrates are discussed in this section.

The lipid reduction rate constant $(k)$ estimated for the exponential model is lower than the Fitzhugh model in most cases, and higher values were achieved for substrates with higher lipid concentrations. For example, $k$ ranged from $1.41 \mathrm{~d}^{-1}$ to $1.48 \mathrm{~d}^{-1}$ for lipid contents varying from $39 \%$ to $43 \%$, which is five times as much as the sample with a lipid content of $33 \%$. In addition, similar variations in $k$ estimated for the exponential $\left(k_{\mathrm{E}}\right)$ and Fitzhugh models $\left(k_{\mathrm{F}}\right)$ were noticed, with the correlation described by the linear equation:

$$
k_{\mathrm{F}}=0.625 k_{\mathrm{E}}+0.348\left(R^{2}=0.953\right) \text {. }
$$

As shown in Table 4, the lag time $(\lambda)$ is negligible in most of the cases, indicating a quick adaption to the new environment for the microorganisms in the seed sludge, 
collected from a food waste treatment plant. The negative $\lambda$ values for most of the substrates were achieved for the both transference and modified Gompertz models. This may be explained by the high biodegradability of the food waste and the quick consumption of soluble organics in the food waste. For the modified Gompertz model, only substrates M11 and M12, which exhibited presented higher final lipid reductions, had positive $\lambda$ values and varied from $0.20 \mathrm{~d}$ to $0.21 \mathrm{~d}$. This may be due to their higher lipid concentrations and longer lag times. This is because the hydrolysis of carbohydrates is rapid and its main hydrolysate, glucose, represses the degradation enzyme for lipids. Additionally, the limited increase inthe hydrolysis of lipids may result from the high LCFA concentrations, which can cause product inhibition or physically hinder adsorption. Higher $\mu_{\mathrm{m}}$ values were estimated from the transference model $(0.07-1.07)$ compared with the modified Gompertz model $(0.03-0.87)$. The $\mu_{\mathrm{m}}$ values estimated for both models decreased with the increasing carbohydrate content and the decreasing lipid content in the substrates under the mesophilic temperature.

The statistical indicators $\left(R^{2}, \mathrm{RMSE}\right.$, and $\left.\mathrm{AIC}_{\mathrm{c}}\right)$ for the first four models for lipid reduction are shown in Table 4. For the lipids, the highest $R^{2}$ values were obtained from the transference model $(0.7332-0.9467)$ with several exceptions in the exponential model, which had almost the same values as the transference model. The lowest RMSE values were also obtained from the transference model $(0.0514$ 0.0963), followed by the exponential and Fitzhugh models (0.0577 - 0.1149), whereas the modified Gompertz model exhibited the highest RMSE. The lowest 
$\mathrm{AIC}_{\mathrm{c}}$ values were obtained from the exponential model in most cases (-133 - -90), followed by transference (ranging from -108 to -86) and Fitzhugh models (-104-79), with the modified Gompertz model exhibiting the highest values (-98 - -82). The lowest RMSE and the lowest $\mathrm{AIC}_{\mathrm{c}}$ values between the predicted and measured lipid reductions indicated that the transference model is the best for fitting to the lipid reduction data, which is also strongly supported by the highest $R^{2}$ values. However, the modified Gompertz model exhibited the overall lowest $R^{2}$ values, but the highest RMSE and $\mathrm{AIC}_{\mathrm{c}}$ values, indicating a relatively inaccurate for lipid reduction. 
Table 4. Estimated parameters for the five models and the $R^{2}, \mathrm{RMSE}$ and $\mathrm{AIC}_{\mathrm{c}}$ values for the different models based on lipid reduction.

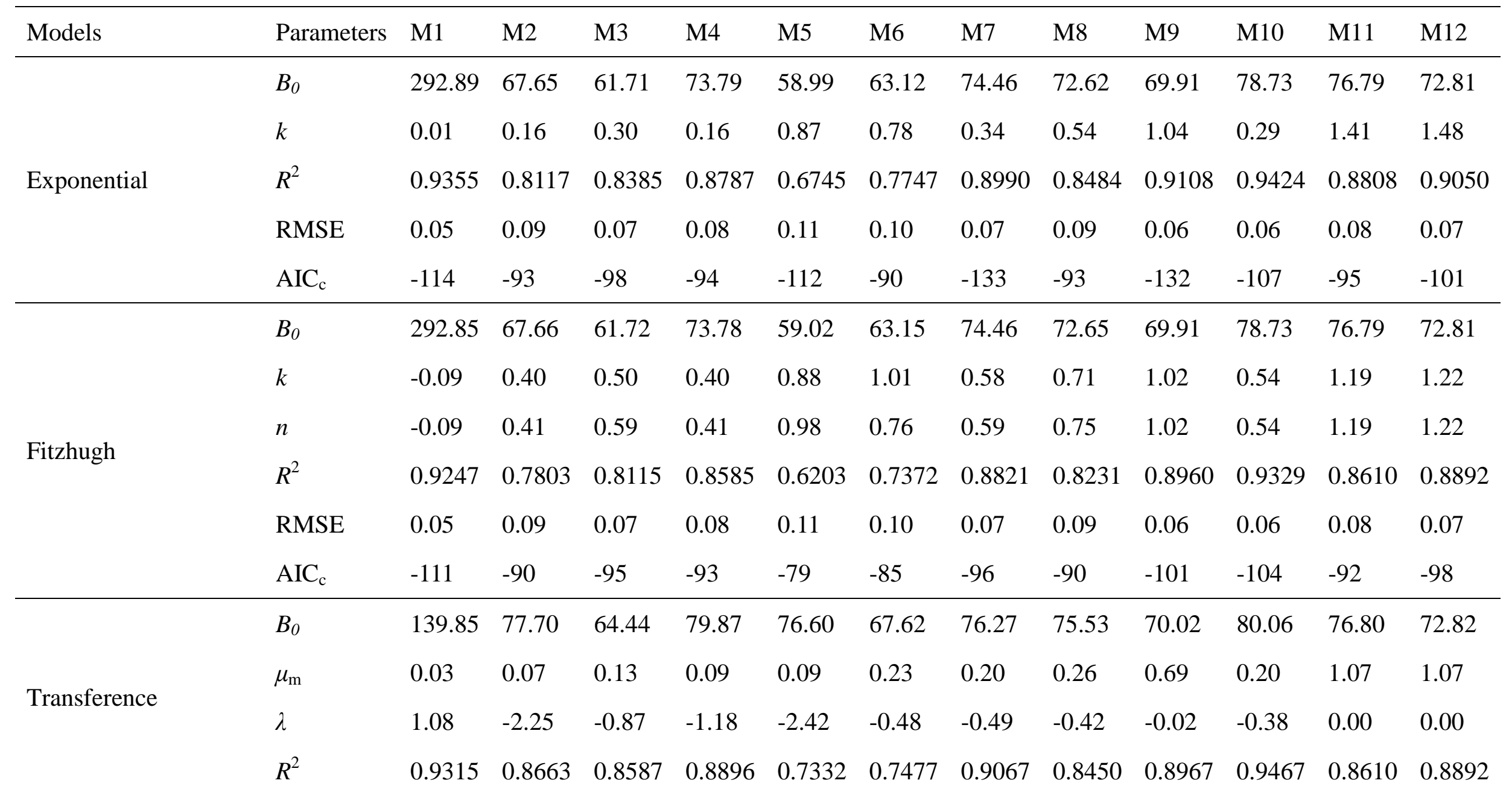




\begin{tabular}{|c|c|c|c|c|c|c|c|c|c|c|c|c|c|}
\hline & RMSE & 0.05 & 0.07 & 0.06 & 0.07 & 0.10 & 0.09 & 0.06 & 0.08 & 0.06 & 0.05 & 0.08 & 0.07 \\
\hline \multirow{5}{*}{ Gompertz } & $B_{0}$ & 37.66 & 75.18 & 64.17 & 78.42 & 76.61 & 68.19 & 75.79 & 75.93 & 68.80 & 78.88 & 76.30 & 72.45 \\
\hline & $\mu_{\mathrm{m}}$ & 0.06 & 0.03 & 0.06 & 0.04 & 0.04 & 0.09 & 0.10 & 0.11 & 0.67 & 0.10 & 0.87 & 0.85 \\
\hline & $\lambda$ & 4.81 & -4.99 & -2.42 & -3.49 & -5.68 & -1.83 & -1.50 & -1.57 & 0.18 & -1.19 & 0.20 & 0.21 \\
\hline & RMSE & 0.07 & 0.07 & 0.07 & 0.08 & 0.10 & 0.10 & 0.08 & 0.09 & 0.07 & 0.07 & 0.08 & 0.07 \\
\hline & $\mathrm{AIC}_{\mathrm{c}}$ & -146 & -95 & -96 & -91 & -84 & -83 & -94 & -87 & -98 & -98 & -91 & -97 \\
\hline \multirow{4}{*}{ Cone $^{a}$} & $B_{0}$ & - & 32394 & 3583 & 12166 & 20388 & 9242 & 137 & 1269 & 105 & 115 & 2183 & 807 \\
\hline & $k$ & - & 0.00 & 0.00 & 0.00 & 0.00 & 0.00 & 0.08 & 0.00 & 0.66 & 0.19 & 0.00 & 0.00 \\
\hline & RMSE & - & 0.03 & 0.03 & 0.04 & 0.05 & 0.04 & 0.03 & 0.03 & 0.03 & 0.02 & 0.03 & 0.03 \\
\hline & $\mathrm{AIC}_{\mathrm{c}}$ & - & -124 & -128 & -118 & -109 & -117 & -130 & -126 & -128 & -142 & -130 & -128 \\
\hline
\end{tabular}

\footnotetext{
${ }^{\mathrm{a}}$ Fit status: Failed.
} 


\subsubsection{Characteristics of protein degradation}

The first four models estimated similar ultimate protein reductions $\left(B_{0}\right)$ for all 12 types of substrates $(48.65-60.28 \%)$, whereas the Cone model predicted the worst results (Table 5). Similar protein reduction rate constants $(k)$ were estimated for the exponential and Fitzhugh models, which fell within the range from $0.79-2.83 \mathrm{~d}^{-1}$ and $0.89-1.73 \mathrm{~d}^{-1}$, respectively. Relatively low values could be achieved in some cases for the Fitzhugh model compared to the exponential model. In addition, the $k$ value for protein reduction was higher than that for lipid reduction. This may be due to the higher hydrolysis rate constant for protein $\left(0.015-0.075 \mathrm{~d}^{-1}\right)$ compared to lipids $\left(0.005-0.010 \mathrm{~d}^{-1}\right)$ [40], indicating a quicker reduction of protein. The $\mu_{\mathrm{m}}$ values estimated from the transference model ranged from 0.42 to 1.58 , whereas a range from $0.37-1.69$ was achieved for $\mu_{\mathrm{m}}$ when estimated using the modified Gompertz model. The lag time determined from the transference model was negligible for all 12 types of substrates, whereas the $\lambda$ ranged from 0.18 to 0.71 , as estimated according to the modified Gompertz model.

The statistical indicators $\left(R^{2}, \mathrm{RMSE}\right.$, and $\left.\mathrm{AIC}_{\mathrm{c}}\right)$ for the first four models for protein reduction are shown in Table 5. The predicted protein reduction during the digestion process derived from the first four proposed models. The highest $R^{2}$ values were observed from the exponential model $(0.8932-0.9951)$, followed by the Fitzhugh and transference models, which had the same values $(0.8754-0.9943)$. Furthermore, the lowest RMSE and $\mathrm{AIC}_{\mathrm{c}}$ values were obtained from the exponential model (0.0111 - 0.0522 and $-167--111$, respectively). The RMSE and $\mathrm{AIC}_{\mathrm{c}}$ values 
calculated by the Fitzhugh and transference models were similar, with only one exception (the modified Gompertz model, in most cases). The $\mathrm{AIC}_{\mathrm{c}}$ values for the predicted protein reduction calculated by the modified Gompertz, Fitzhugh, and transference models show little difference. Therefore, the exponential model is best for fitting the protein reduction data. 
Table 5. Estimated parameters for the five models and the $R^{2}, \mathrm{RMSE}$ and $\mathrm{AIC}_{\mathrm{c}}$ values for the different models based on protein reduction.

\begin{tabular}{|c|c|c|c|c|c|c|c|c|c|c|c|c|c|}
\hline Models & Parameters & M1 & M2 & M3 & M4 & M5 & M6 & M7 & M8 & M9 & M10 & M11 & M12 \\
\hline \multirow{3}{*}{ Exponential } & $k$ & 1.02 & 1.53 & 2.06 & 1.35 & 0.89 & 2.98 & 1.63 & 1.79 & 2.83 & 1.48 & 0.79 & 2.04 \\
\hline & $R^{2}$ & 0.9830 & 0.9473 & 0.9951 & 0.9592 & 0.9719 & 0.9173 & 0.9859 & 0.9631 & 0.8932 & 0.9522 & 0.9702 & 0.9793 \\
\hline & RMSE & 0.02 & 0.04 & 0.01 & 0.03 & 0.03 & 0.05 & 0.02 & 0.03 & 0.05 & 0.03 & 0.03 & 0.03 \\
\hline \multirow{4}{*}{ Fitzhugh } & $B_{0}$ & 49.72 & 51.45 & 54.31 & 48.65 & 53.56 & 53.05 & 53.74 & 51.43 & 51.99 & 53.14 & 53.20 & 60.28 \\
\hline & $k$ & 1.04 & 1.24 & 1.43 & 1.12 & 0.94 & 1.73 & 1.28 & 1.34 & 1.68 & 1.21 & 0.89 & 1.43 \\
\hline & $n$ & 1.04 & 1.24 & 1.43 & 1.21 & 0.94 & 1.73 & 1.28 & 1.34 & 1.68 & 1.21 & 0.89 & 1.43 \\
\hline & $R^{2}$ & 0.9890 & 0.9385 & 0.9943 & 0.9524 & 0.9673 & 0.9035 & 0.9835 & 0.9570 & 0.8754 & 0.9442 & 0.9653 & 0.9758 \\
\hline \multirow{4}{*}{ Transference } & $B_{0}$ & 49.32 & 51.45 & 54.31 & 48.65 & 53.56 & 53.05 & 53.74 & 51.43 & 51.99 & 53.14 & 53.21 & 60.28 \\
\hline & $\mu_{\mathrm{m}}$ & 0.50 & 0.78 & 1.12 & 0.66 & 0.48 & 1.58 & 0.88 & 0.92 & 1.47 & 0.78 & 0.42 & 1.23 \\
\hline & $\lambda$ & -0.01 & 0.00 & 0.00 & 0.00 & 0.00 & 0.00 & 0.00 & 0.00 & 0.00 & 0.00 & -0.01 & 0.00 \\
\hline & $R^{2}$ & 0.9802 & 0.9385 & 0.9943 & 0.9524 & 0.9673 & 0.9035 & 0.9835 & 0.9570 & 0.8754 & 0.9442 & 0.9654 & 0.9758 \\
\hline
\end{tabular}




\begin{tabular}{|c|c|c|c|c|c|c|c|c|c|c|c|c|c|}
\hline & RMSE & 0.02 & 0.04 & 0.01 & 0.03 & 0.03 & 0.05 & 0.02 & 0.03 & 0.05 & 0.03 & 0.03 & 0.03 \\
\hline \multirow{5}{*}{ Gompertz } & $B_{0}$ & 49.67 & 51.22 & 54.29 & 48.48 & 53.08 & 53.05 & 53.72 & 51.36 & 51.99 & 53.00 & 52.35 & 60.25 \\
\hline & $\mu_{\mathrm{m}}$ & 0.56 & 0.61 & 0.81 & 0.54 & 0.39 & 1.01 & 1.69 & 0.68 & 0.95 & 0.62 & 0.37 & 0.88 \\
\hline & $\lambda$ & 0.38 & 0.21 & 0.26 & 0.25 & 0.21 & 0.23 & 0.71 & 0.24 & 0.23 & 0.24 & 0.18 & 0.25 \\
\hline & RMSE & 0.02 & 0.04 & 0.01 & 0.03 & 0.03 & 0.05 & 0.02 & 0.03 & 0.05 & 0.04 & 0.03 & 0.03 \\
\hline & $\mathrm{AIC}_{\mathrm{c}}$ & -115 & -125 & -122 & -108 & -128 & -146 & -112 & -130 & -128 & -163 & -121 & -155 \\
\hline \multirow{4}{*}{ Cone } & $A$ & 52.30 & 60.41 & 54.72 & 67.67 & 53.39 & 248.75 & 53.72 & 403.97 & 479.95 & 73.84 & 58.16 & 292.41 \\
\hline & $k$ & 1.72 & 4.61 & 3.39 & 1.99 & 1.12 & 0.00 & 1.10 & 0.00 & 0.00 & 3.39 & 1.16 & 0.00 \\
\hline & RMSE & 0.01 & 0.02 & 0.01 & 0.02 & 0.03 & 0.04 & 0.02 & 0.01 & 0.04 & 0.03 & 0.02 & 0.01 \\
\hline & $\mathrm{AIC}_{\mathrm{c}}$ & -155 & -122 & -164 & -128 & -131 & -112 & -144 & -129 & -108 & -122 & -130 & -133 \\
\hline
\end{tabular}




\subsection{Evaluation of the kinetic models for organics degradation}

It has been suggested that the hydrolysis constant $(k)$ may not be a universal constant because it is specifically calculated for a given sample under certain conditions [18]. In this study, the degradation properties of the organic compositions for 12 types of food waste containing a large range of organic contents were studied and compared using five models. The statistical indicators $\left(R^{2}, \mathrm{RMSE}\right.$, and $\left.\mathrm{AIC}_{\mathrm{c}}\right)$ for the five models for organics reduction are shown in Table $\mathbf{2}-\mathbf{5}$. In general, the exponential model is best for fitting the reduction data for protein, total solids, and volatile solids compared to the transference model for lipid reduction data. Meanwhile, an inadequate fit was observed in each case for the modified Gompertz model based on having the lowest $R^{2}$ and highest RMSE and $\mathrm{AIC}_{\mathrm{c}}$ values in most cases, whereas the Cone model exhibited the worst fit between the model values and experimental data. Higher $R^{2}$ and simultaneously lower RMSE and $\mathrm{AIC}_{\mathrm{c}}$ values are observed for the total solids and volatile solids compared with the proteins and lipids, indicating an accurate fit for complex heterogeneous substrates in terms of volatile solids and total solids. However, the Cone model does not process good agreement for the overall fitting process. At the digestion start time $(t=0)$, there should be no organics degradation, whereas the reduction of organics (e.g., total solids, volatile solids, proteins, and lipids) is not zero amount predicted by Cone model. Therefore, the Cone model cannot make useful predictions.

In addition, for the final lipid reduction from sample M1 with the highest carbohydrate content $(73.30 \%$, total solid \%), inaccurate results could be estimated 
for the five models, despite higher $R^{2}$ values being achieved. Therefore, it is necessary to consider other statistical indicators, such as RMSE and $\mathrm{AIC}_{\mathrm{c}}$ simultaneously, instead of only $R^{2}$ when the kinetics models are applied. These conclusions agree with those drawn from previous research; Eastman and Ferguson [43] reported that first-order kinetics are the most appropriate empirical hydrolysis function for complex heterogeneous substrates such as primary sludge under acidogenic conditions, whereas other hydrolysis functions may be more appropriate for single homogeneous substrates. Furthermore, previous researchers reported that the modified Gompertz model can be easily used to describe the progress of food waste degradation and showed good agreement with the experimental result [44-47]. Meanwhile, other studies concluded that using modified Gompertz model can obtain some constants that have biological meanings, which may be of great importance to a better understanding of a process [46]. According to Pitt et al. [27], the interpretation of gas model parameters may be difficult to interpret and models with several parameters may not permit straightforward comparisons among the different feeds.

Another obvious phenomenon is that the transference model predicted negative $\lambda$ values for most of the estimations that were supposed to be non negative. It may be concluded that the transference model cannot simulate the lag time appropriately. This result is in accordance with previous conclusions reported by Huiliñir et al [48] that the transference model can only be used if the lag phase is close to zero. Although the modified Gompertz model exhibited higher RMSE and $\mathrm{AIC}_{\mathrm{c}}$ and lower 
$R^{2}$ values in most cases compared to other three models, the differences in these values is very small compared to those estimated by the other three models. Therefore, the modified Gompertz model also fits the experimental data well when the lag phase is estimated. Thus, both the exponential and modified Gompertz models concur with the experimental data and the former possesses the best fit.

\subsection{Impact of the organics degradation on methane production}

\subsubsection{Effects of organic reduction and methane yield}

To evaluate the interaction of organic components with biomethane yield, the exponential model, which is the best model for fitting the reduction of protein, total solids, and volatile solids, was used to simulate the methane yield processes with the degradation of the organics. The cumulative methane production increased exponentially with the removal efficiency of the volatile solids, lipids, and proteins for all 12 substrates (Fig. $1-3$ ). The estimated parameters derived from these fitted models are shown in Table 6. Higher $R^{2}$ values were obtained from the regressions models indicated consistency with the experimental data. The exponential relationship between the methane yield and organics reduction may be estimated with the exception of sample M1, which indicated a very quick biomethane conversion. This may be due to its very simple composition and the exponential function being inappropriate for single homogeneous substrates instead of more complex heterogeneous organic components [43]. It may be concluded that the hydrolysis rate of complex material limits its overall biomethane production rate when refractory organic compounds, such as lipids and proteins are the main 
substrates for an anaerobic digester.

Different relationships between the methane yield and protein reduction were found by Yang et al [49] who found that the cumulative biogas production increased linearly with the removal efficiency during sludge digestion performed at $36 \pm 1{ }^{\circ} \mathrm{C}$. This may be due to differences in the protein types between sewage sludge and food waste. Furthermore, the characteristics of the substrate can influence the degradation patterns for protein, such as the floc structure in sludge.

The final methane yield (385 to $627 \mathrm{~mL} / \mathrm{g}$ volatile solid) was statistically and positively correlated with the lipid $(p<0.01)$ content, but negatively with carbohydrate content $(p<0.05)$ and carbohydrate: protein: lipid ratios $(p<0.05)$, while it had no significant differences from protein concentration and $\mathrm{C} / \mathrm{N}$ ratios (Table 1b). These findings were due to that lipid had the highest biomethane production potential and carbohydrate lower values among these organic components. Besides, the findings also suggest that the carbohydrate: protein: lipid ratios could be more appropriate and reasonable compared to $\mathrm{C} / \mathrm{N}$ ratios when used as an important indicator for digestion performance. Organics degradation contributes to methane production during anaerobic digestion process, and significant and positive correlation between volatile solid, protein and lipid $(p<0.01)$ reduction and methane yield could be achieved (Table S3).

After volatile solid reduction and protein reduction achieved higher than about $50 \%$ (Fig. 1), methane production in all samples was increased sharply, especially for the food waste with higher carbohydrate content and lower lipid content. The lower 
methane yield when organics reduction was less than $50 \%$ could be due to the solubilisation hydrolysis of organics. Besides, during this process, the microorganisms could have completed the acclimatization to the surroundings. In addition, microorganisms responsible for the degradation of specific organic matters might have begun to expand faster and dominate.

In addition, as shown Fig. 1(c), Due to organic composition, samples with carbohydrate: protein: lipid ratios lower than 1.98 (sample M8 - M 12) had negative $R_{0}$ in exponential function compared with affirmative values for those with ratios higher than 1.98. These results could be due to the high hydrolysis rate of carbohydrate during the anaerobic digestion process, compared to lipids and proteins.

\subsubsection{Interaction of organic component reduction}

Fig. 2 shows that protein degradation increased exponentially with the removal efficiency of lipid. More lipids (59-79\%) could be degraded after digestion compared with proteins (47-60\%). Besides, higher degradation rates were achieved for proteins compared with lipids. As shown in Table 6, according to the regression models between protein reduction and lipid reduction, relatively lower $k$ values were achieved for samples with lower carbohydrate: protein: lipid ratios. A possible reason could be long chain fatty acid accumulation due to the hydrolysis of lipids for samples with higher lipid content during digestion process, thus inhibition of long chain fatty acid occurred. This could also delay the degradation of proteins and other organics. However, lipid-rich feedstock has higher biochemical methane potential 
than carbohydrate-rich and protein-rich feedstocks, considering the appropriate carbohydrate: protein: lipid ratio, to obtain higher biogas/biomethane production, the lipid content in food waste was suggested to be less than $28 \%$ (dry basis).

For the organics composition, the volatile solid reduction increased exponentially and linearly, respectively, with the removal efficiency of the lipids and proteins (Fig. 3). As shown in Fig. 3 a, the linear relationship between the volatile solid reduction and the protein reduction indicated that protein was reduced and contributed to the reduction of volatile solids which were steadily converted into biogas during the entire digestion process. These relationships also indicated that the degradation of organics had a significant impact on the anaerobic digestion performance of the food waste.

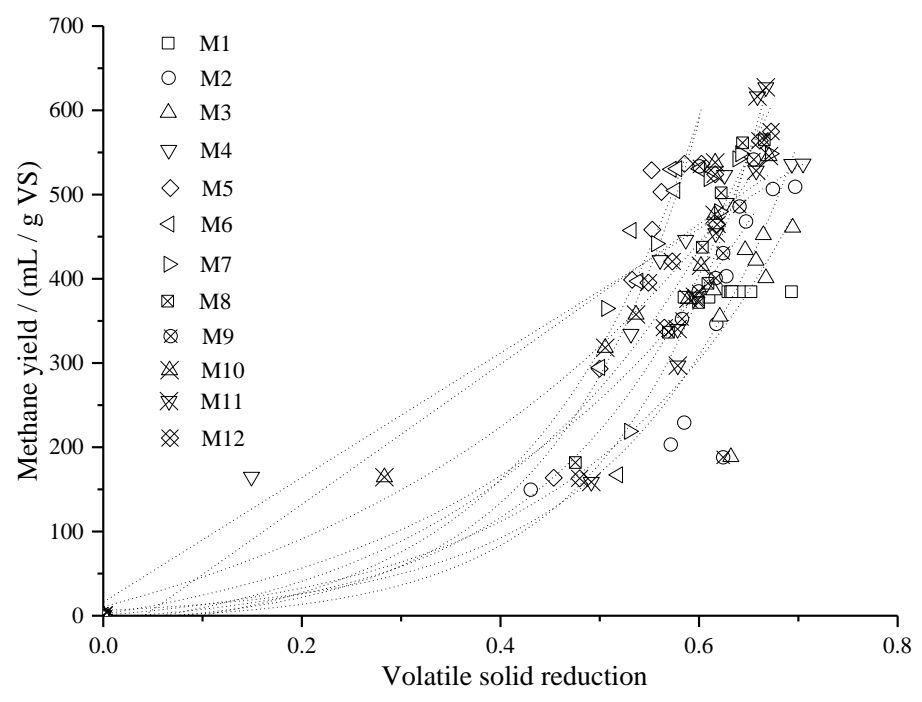

(a) 


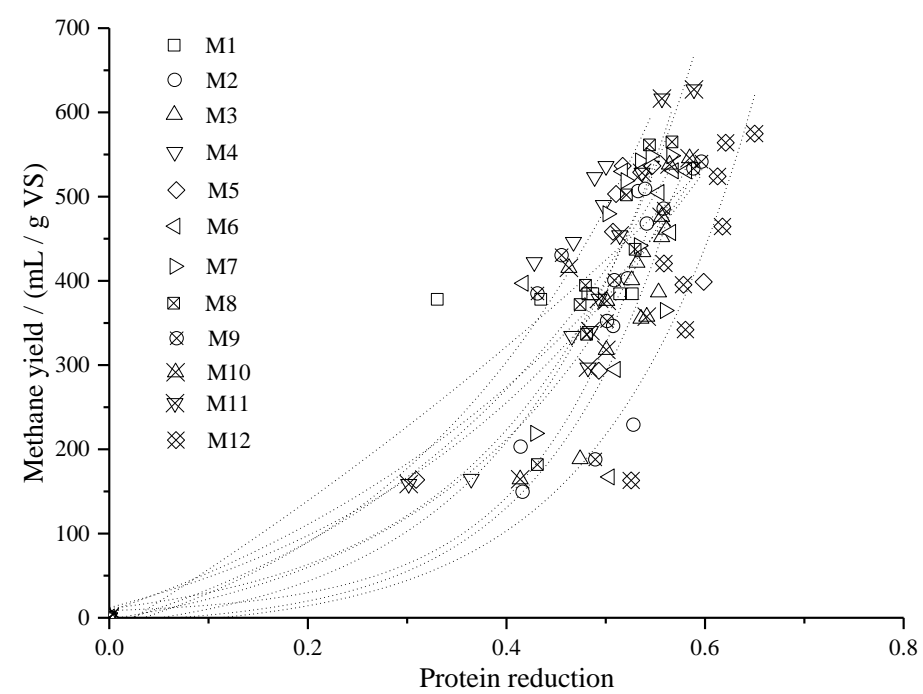

(b)

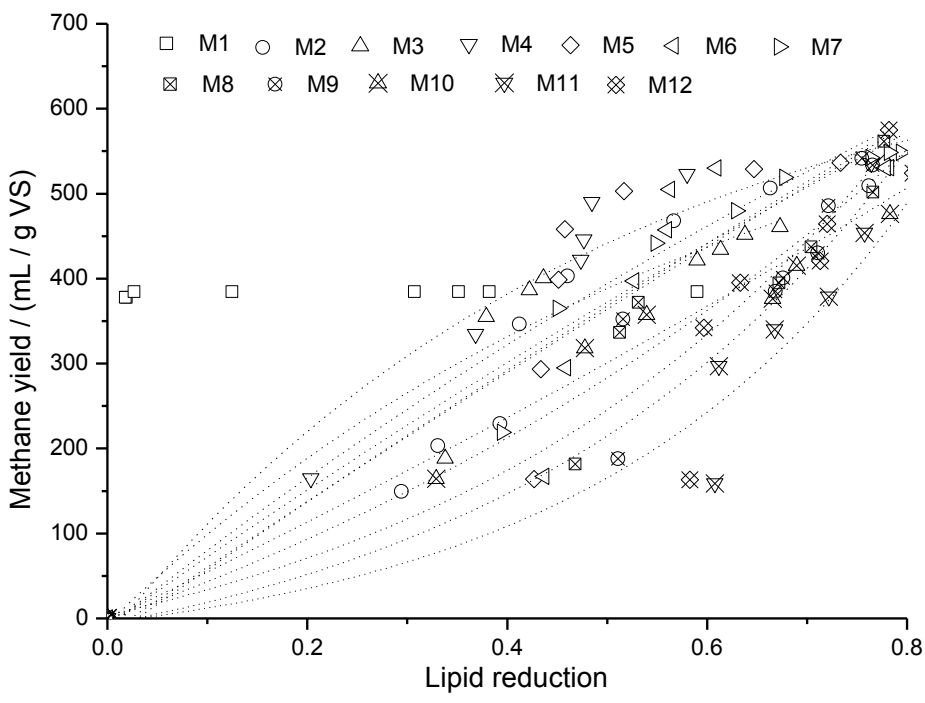

(c)

Fig. 1. The relationship between the organics reduction (volatile solids (a)), proteins

(b), and lipids (c)) and methane yield. 


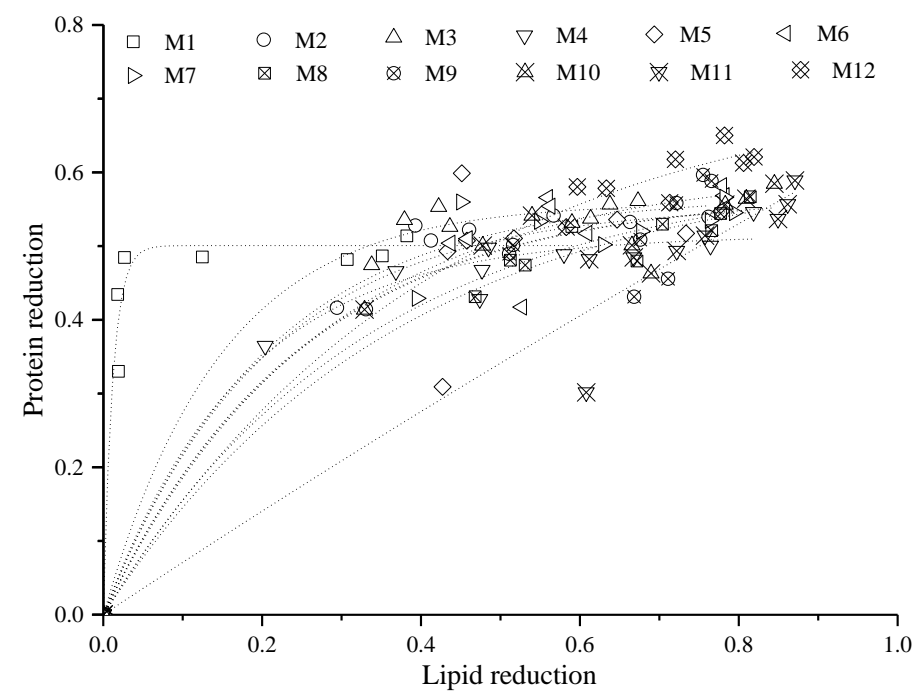

Fig. 2. The relationship between the protein and lipid reduction.

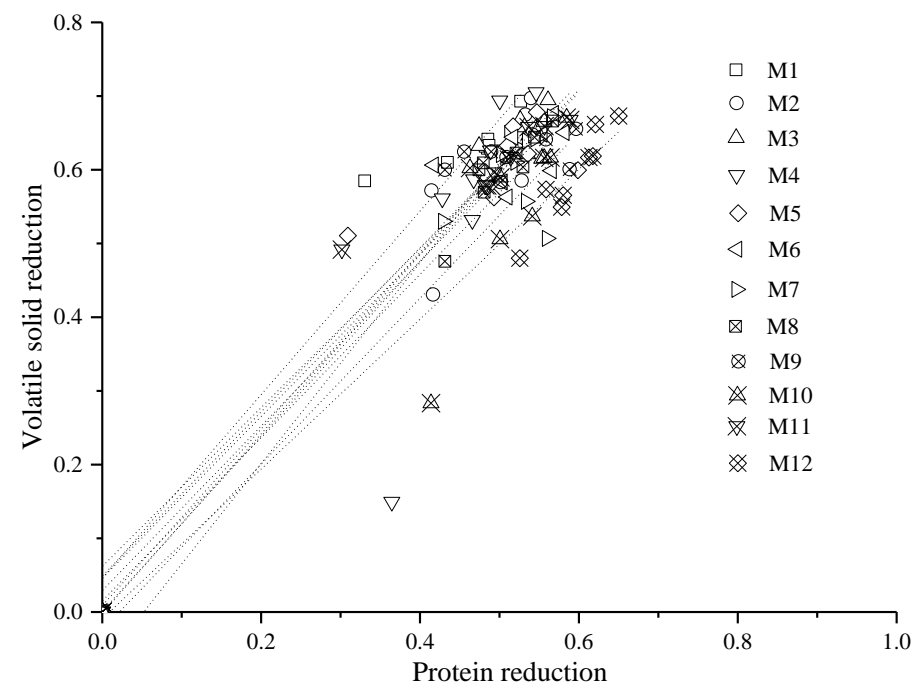

(a) 


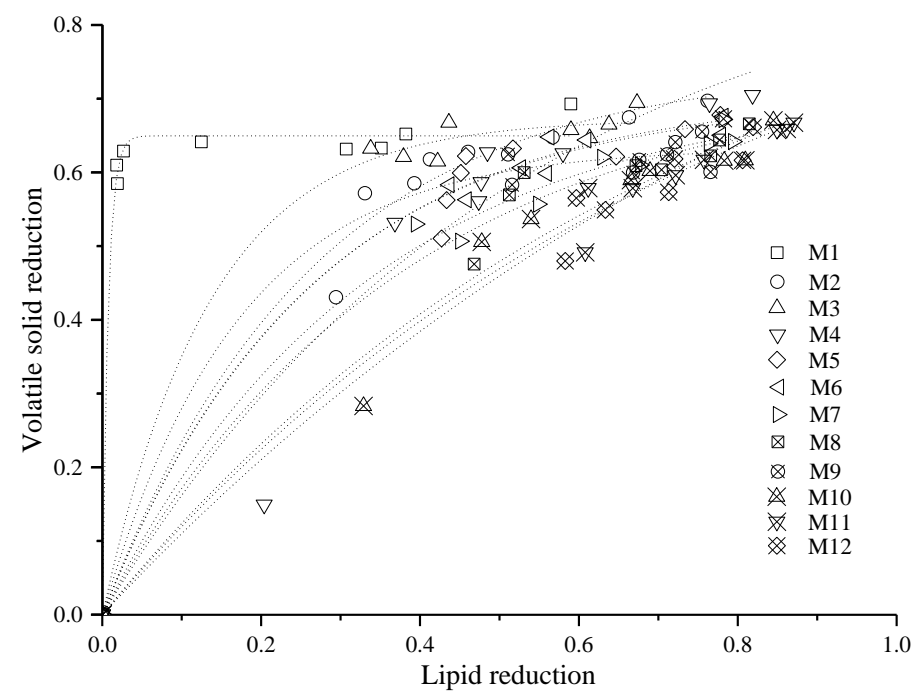

(b)

Fig. 3. The relationship between the reduction of protein (a) and lipid (b) and volatile solid reduction. 
Table 6.

The relationship between organics reduction and methane production using the exponential model.

\begin{tabular}{llllllllllll}
\hline Parameters & M1 & M2 & M3 & M4 & M5 & M6 & M7 & M8 & M9 & M10 & M11 \\
\hline
\end{tabular}

1. Relationship between methane yield $\left(\mathrm{CH}_{4}\right)$ and volatile solid reduction $(\Delta \mathrm{VS})$ using exponential model $\left(\mathrm{CH}_{4}=y_{0}+A * \exp \left(R_{0} * \Delta \mathrm{VS}\right)\right)$

\begin{tabular}{lccccccccccccccccccccc}
\hline$y_{0}$ & - & -2.86 & -22.55 & 77118 & -33.58 & -15.33 & 208237 & -16.11 & -53.91 & -113.99 & -8.53 & -52.20 \\
$A$ & - & 8.78 & 22.65 & -77102 & 18.92 & 9.13 & -208272 & 13.15 & 55.25 & 124.44 & 5.13 & 40.58 \\
$R_{0}$ & - & 5.95 & 4.45 & -0.01 & 5.19 & 6.21 & 0.00 & 5.77 & 3.45 & 2.50 & 7.21 & 4.14 & \\
$R^{2}$ & - & 0.9216 & 0.7359 & 0.9548 & 0.9122 & 0.8042 & 0.7897 & 0.9670 & 0.5485 & 0.9482 & 0.9790 & 0.9282 \\
\hline
\end{tabular}

2. Relationship between methane yield $\left(\mathrm{CH}_{4}\right)$ and protein reduction $(\Delta \mathrm{CP})$ using exponential model $\left(\mathrm{CH}_{4}=y_{0}+A * \exp \left(R_{0} * \Delta \mathrm{CP}\right)\right)$

\begin{tabular}{|c|c|c|c|c|c|c|c|c|c|c|c|c|}
\hline$A$ & - & 4.91 & 6.93 & 94.25 & 943.39 & 102.01 & 114.61 & 23.47 & 177.89 & 42.09 & 25.50 & 8.43 \\
\hline$R_{0}$ & - & 8.36 & 7.56 & 3.68 & 0.77 & 3.05 & 3.09 & 5.82 & 2.29 & 4.51 & 5.58 & 6.66 \\
\hline$R^{2}$ & - & 0.7646 & 0.9099 & 0.8546 & 0.7205 & 0.5687 & 0.7594 & 0.9218 & 0.7124 & 0.8455 & 0.9492 & 0.8720 \\
\hline
\end{tabular}


3. Relationship between methane yield $\left(\mathrm{CH}_{4}\right)$ and lipid reduction $(\triangle \mathrm{EE})$ using exponential model $\left(\mathrm{CH}_{4}=y_{0}+A * \exp \left(R_{0} * \Delta \mathrm{EE}\right)\right)$

\begin{tabular}{rrrrrrrrrrrrrrrrrrrrr}
\hline$y_{0}$ & - & 4194 & 730 & 710 & 1602 & 6006 & 2445 & -367 & -119 & -1780 & -53.08 & -101 \\
$A$ & - & -4218.41 & -735.91 & -731.96 & -1612 & -6024 & -2454.07 & 365.46 & 122.28 & 1778.46 & 48.03 & 93.67 \\
$R_{0}$ & - & -0.19 & -1.53 & -2.00 & -0.58 & -0.13 & -0.34 & 1.15 & 2.18 & 0.31 & 3.03 & 2.43 \\
$R^{2}$ & - & 0.8917 & 0.8838 & 0.9470 & 0.7371 & 0.7861 & 0.9530 & 0.9267 & 0.9152 & 0.9728 & 0.9431 & 0.8841 \\
\hline
\end{tabular}

4. Relationship between volatile solid reduction $(\Delta \mathrm{VS})$ and lipid reduction $(\Delta \mathrm{EE})$ using exponential model $(\Delta \mathrm{VS}=A *(1-\exp (-k * \Delta \mathrm{EE})))$

\begin{tabular}{lllllllllllllll}
\hline$A$ & 0.65 & 0.74 & 0.67 & 0.93 & 0.71 & 0.70 & 0.71 & 0.73 & 0.63 & 0.96 & 0.99 & 1.21 \\
$k$ & 134.83 & 3.80 & 7.40 & 1.91 & 3.79 & 3.87 & 3.02 & 2.66 & 5.85 & 1.38 & 1.29 & 0.95 \\
$R^{2}$ & 0.9904 & 0.9763 & 0.9919 & 0.9239 & 0.9786 & 0.9931 & 0.9897 & 0.9814 & 0.9894 & 0.9725 & 0.9879 & 0.9791 \\
\hline
\end{tabular}

5. Relationship between volatile solid reduction $(\triangle \mathrm{VS})$ and protein reduction $(\Delta \mathrm{CP})$ using linear model $(\Delta \mathrm{VS}=a+b * \Delta \mathrm{CP})$

\begin{tabular}{lllllllllllllll}
\hline$a$ & 0.05 & 0.00 & 0.01 & -0.07 & 0.06 & 0.03 & 0.02 & 0.00 & 0.05 & -0.02 & 0.05 & -0.01 \\
$b$ & 1.25 & 1.22 & 1.20 & 1.36 & 1.08 & 1.12 & 1.11 & 1.19 & 1.10 & 1.12 & 1.11 & 1.02 \\
$R^{2}$ & 0.9335 & 0.9509 & 0.9745 & 0.7825 & 0.8928 & 0.9327 & 0.9134 & 0.9834 & 0.9087 & 0.8639 & 0.9491 & 0.9816 \\
\hline
\end{tabular}


6. Relationship between protein reduction $(\Delta \mathrm{CP})$ and lipid reduction $(\Delta \mathrm{EE})$ using exponential model $(\Delta \mathrm{CP}=A *(1-\exp (-k * \Delta \mathrm{EE})))$

\begin{tabular}{llllllllllllllll}
\hline$A$ & 0.50 & 0.57 & 0.56 & 0.51 & 0.57 & 0.60 & 0.56 & 0.61 & 0.60 & 0.57 & 3.67 & 0.73 \\
$k$ & 84.07 & 4.86 & 6.77 & 5.67 & 4.06 & 3.68 & 4.92 & 2.71 & 2.99 & 4.01 & 0.20 & 2.39 \\
$R^{2}$ & 0.9498 & 0.9778 & 0.9893 & 0.9743 & 0.8252 & 0.9418 & 0.9634 & 0.9881 & 0.9083 & 0.9601 & 0.9189 & 0.9848 \\
\hline
\end{tabular}


3.4.3. Possible strategies for improving methane yield from anaerobic digestion

In general, food waste substrates with different organics compositions have varied hydrolysis constants ( $R_{0}$ in the exponential function and $b$ in the linear function). Small variations in the organics compositions of food waste can have a significant influence on the hydrolysis constant. Therefore, it can be concluded that kinetic parameters, such as the hydrolysis constant, might not be commonly used for all situations even though good correlation coefficients $\left(R^{2}\right)$ are achieved.

However, these relationships can indicate that the degradation of organics compositions, such as proteins, lipids, and volatile solids, have major impacts on the anaerobic digestion performance of organics, such as food waste. Thus, a possible strategy for predicting the digestion parameters (e.g., methane yield, organics reduction, and corresponding organics reduction) for food waste is to analyse the protein and lipid compound content in the digestate. Additionally, it should be noted that it is difficult to control the feedstock compositions during anaerobic digestion process for pilot projects. Based on above analysis, organics reduction that included protein reduction, lipid reduction and volatile solid reduction, had major influences on methane yield. A significant correlation was found between these organics reduction and methane yield (Table S3). Therefore, monitoring the organic degradation efficiency could be a simplified and effective way to predict the methane yield from food waste.

After independent variables testing (Table S1 and Table 7), the VS reduction ( $\Delta$ VS) and $\mathrm{EE}$ reduction $(\triangle \mathrm{EE})$ were selected as independent variables, and the methane yield 
$\left(\mathrm{CH}_{4}\right)$ was selected as the dependent variables. The final second-order polynomial which was based on the experimental data in terms of actual factors was obtained as follows:

$$
\mathrm{CH}_{4}=106.68-313.44 \Delta \mathrm{EE}+576.50 \Delta \mathrm{EE}^{2}+737.62 \Delta \mathrm{VS}^{2}
$$

The $R^{2}$ value was 0.714 , indicating that the data can be well explained by these models. Additionally, the terms $E E \times V S$ and $V S$ were removed from the final polynomial to achieve a lower $p$ value (their coefficients were set to zero). The $p$ value was lower than 0.01 (Table S1), so we can concluded that the model term was significant.

Table 7. Coefficients from the regression models.

\begin{tabular}{|c|c|c|c|c|c|c|c|c|c|}
\hline \multicolumn{2}{|c|}{ Independent variables } & \multicolumn{6}{|c|}{$M=M_{0}+\boldsymbol{a} X+\boldsymbol{b} Y+\boldsymbol{c} X^{2}+\boldsymbol{d} Y^{2}+\boldsymbol{f} X Y$} & \multirow{2}{*}{$R^{2}$} & \multirow{2}{*}{$p_{\max } *$} \\
\hline$X$ & $Y$ & $M_{0}$ & $a$ & $b$ & $c$ & $d$ & $f$ & & \\
\hline$\triangle C P$ & $\triangle E E$ & 46.64 & 747.55 & -540.51 & 0.00 & 796.09 & 0.00 & 0.648 & 0.515 \\
\hline$\triangle C P$ & $\Delta V S$ & 33.25 & 666.30 & -1117.01 & 0.00 & 1922.10 & 0.00 & 0.647 & 0.803 \\
\hline$\Delta E E$ & $\Delta V S$ & 106.68 & -313.44 & 0.00 & 576.50 & 737.62 & 0.00 & 0.714 & 0.0311 \\
\hline
\end{tabular}

${ }^{*} p_{\max }:$ the highest $p$ value for each coefficient.

Additionally, the predicted methane yield value of each run was presented in Fig. 4. The $R^{2}$ value for the predicted model was 0.9777 , indicating that the data can be well explained by the model, as the $R^{2}$ value is greater than 0.75 [50]. 


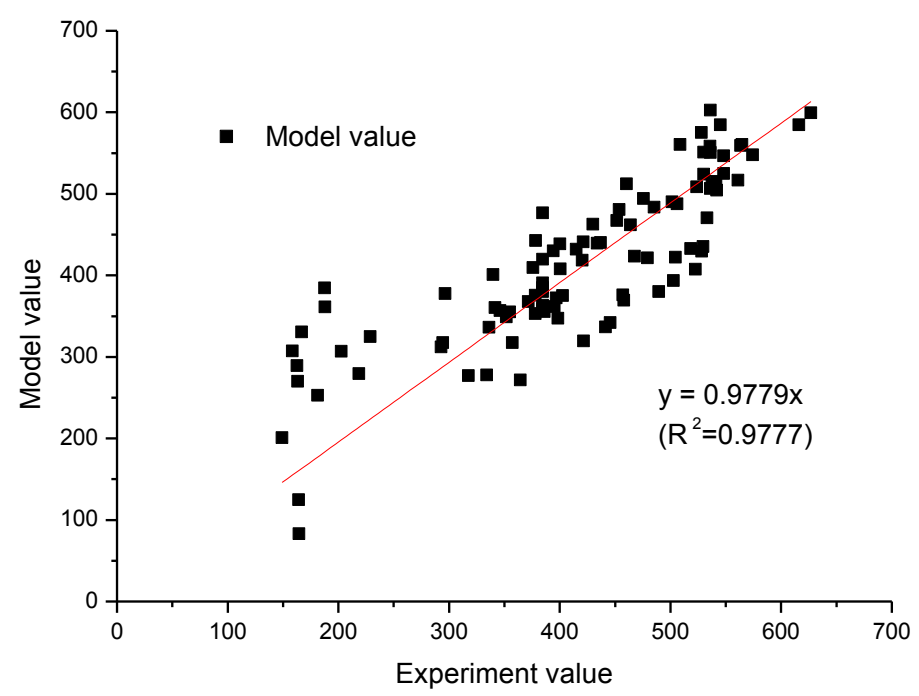

Fig. 4. The relationship between the predicted and measured methane yield.

The optimal methane yield was calculated to be $600 \mathrm{~mL} / \mathrm{g} \mathrm{VS}$ (the measured value was $627 \mathrm{~mL} / \mathrm{g}$ VS) at VS reduction of $66.72 \%$ and EE reduction of $87.07 \%$, respectively. However, as discussed in our previous work [51,52], a longer digestion retention time will be needed $(409 \mathrm{~h})$, which is tough to achieve in practice. A shorter retention time is always preferred due to cost and time savings, while a relatively higher methane production is good for obtaining a higher output for a digestion system of food waste. Therefore, for optimum VS and EE reduction to achieve relatively higher methane yield and shorter digestion duration, reductions of $65.01-67.77 \%$ and $77.80-79.41 \%$ were preferred to obtain optimum economic benefits from food waste digestion. Moreover the methane yield ranged from 559 to $586 \mathrm{~mL} / \mathrm{gVS}$, while the digestion duration varied from 196 to $212 \mathrm{~h}$ [51].

For food waste digestion in practice, high methane production with short retention times is always preferred so long as sustainable digestion is guaranteed. Taking the 
relationships between the performance and kinetic parameters and the organic reduction into account, it is necessary to optimize the $\Delta \mathrm{EE}$ and $\Delta \mathrm{VS}$ to achieve a high methane yield without inhibition. The results of a second-order polynomial in terms of the $\triangle \mathrm{EE}$ and $\triangle \mathrm{VS}$ in this study may be taken as a reference for the real applications of food waste for anaerobic digestion to predict the final methane yield, system stability, and avoid inhibition. Besides, the retention duration in the digester could be adjusted based on the research results in this study, while the energy ratio and economic feasibility could also be assessed. Additionally, the organic composition of food waste with carbohydrate content higher than $47.6 \%$, protein content lower than $24.1 \%$, and lipid content lower than $28.3 \%$ (volatile solid basis) achieved better digestion performance.

\section{Conclusions}

This paper investigated the degradation performance of organics (i.e. total solids, volatile solids, lipids, and proteins) and the maximum methane yield of food waste by optimizing organics degradation during food waste digestion. This work showed that the methane yield (385-627 mL/g volatile solid) increased exponentially with the organic reduction, while the volatile solid reduction increased exponentially with the lipid degradation and linearly with protein degradation. The reduction of volatile solids and lipids has significant effects on methane yields and the correlations could be described by the second-order polynomial mode. Higher methane production (530-548 $\mathrm{mL} / \mathrm{g}$ volatile solid) and removal efficiency of the volatile solids (65.0-67.8\%), lipids 
(77.8-78.2\%), and proteins (54.7-58.2\%) could be achieved in a shorter digestion retention (196-212 h) when the carbohydrate content was higher than $47.6 \%$, protein content lower than $24.1 \%$, and lipid content lower than $28.3 \%$. By applying the five simplified and widely applied kinetics models, this work highlighted how the biomethane production performance is affected by organics reductions. It further revealed the important correlation between the organics reduction in terms of the organics reduction in terms of volatile solids, proteins and lipids in food waste. These findings provide important information on how biomethane production can be enhanced and optimized through the improvement of organic degradation.

\section{Acknowledgements}

This work was supported financially by the Major Science and Technology Program for Water Pollution Control and Treatment (2017ZX07202005) and the China Scholarship Council (CSC).

\section{References:}

1. Murphy JD, McKeogh E, Kiely G. Technical/economic/environmental analysis of biogas utilisation. APPL ENERG. 2004;77:407-427.

2. Igoni AH, Ayotamuno MJ, Eze CL, Ogaji S, Probert SD. Designs of anaerobic digesters for producing biogas from municipal solid-waste. APPL ENERG. 2008;85:430-438.

3. Komilis D, Barrena R, Grando RL, Vogiatzi V, Sánchez A, Font X. A state of the art literature review on anaerobic digestion of food waste: influential operating parameters on methane yield. Reviews in Environmental Science and Bio/Technology. 2017:1-14.

4. Arsova L. Anaerobic digestion of food waste: Current status, problems and an alternative product. Department of earth and Environmental Engineering foundation of Engineering and Applied Science Columbia University. 2010.

5. Browne JD, Allen E, Murphy JD. Assessing the variability in biomethane production from the organic fraction of municipal solid waste in batch and continuous operation. APPL ENERG. 
2014;128:307-314.

6. Yin Y, Liu Y, Meng S, Kiran EU, Liu Y. Enzymatic pretreatment of activated sludge, food waste and their mixture for enhanced bioenergy recovery and waste volume reduction via anaerobic digestion. APPL ENERG. 2016;179:1131-1137.

7. Li W, Loh K, Zhang J, Tong YW, Dai Y. Two-stage anaerobic digestion of food waste and horticultural waste in high-solid system. 2017. https://doi.org/10.1016/j.apenergy.2017.05.042. APPL ENERG.

8. Zhang J, Loh K, Li W, Lim JW, Dai Y, Tong YW. Three-stage anaerobic digester for food waste. APPL ENERG. 2017;194:287-295.

9. Kavitha S, Banu JR, Priya AA, Uan DK, Yeom IT. Liquefaction of food waste and its impacts on anaerobic biodegradability, energy ratio and economic feasibility. 2017. https://doi.org/10.1016/j.apenergy.2017.10.049. APPL ENERG.

10. Li Y, Jin Y, Li J, Li H, Yu Z. Effects of thermal pretreatment on the biomethane yield and hydrolysis rate of kitchen waste. APPL ENERG. 2016;172:47-58.

11. Batstone DJ. Mathematical modelling of anaerobic reactors treating domestic wastewater: Rational criteria for model use. Reviews in Environmental Science and Biotechnology. 2006;5:57-71.

12. Donoso-Bravo A, Mailier J, Martin C, Rodríguez J, Aceves-Lara CA, Wouwer AV. Model selection, identification and validation in anaerobic digestion: a review. WATER RES. 2011;45:5347-5364.

13. Li K, Liu R, Sun C. Comparison of anaerobic digestion characteristics and kinetics of four livestock manures with different substrate concentrations. BIORESOURCE TECHNOL. 2015;198:133-140.

14. Kafle GK, Kim SH. Anaerobic treatment of apple waste with swine manure for biogas production: batch and continuous operation. APPL ENERG. 2013;103:61-72.

15. El-Mashad HM. Kinetics of methane production from the codigestion of switchgrass and Spirulina platensis algae. BIORESOURCE TECHNOL. 2013;132:305-312.

16. Weinrich S, Nelles M. Critical comparison of different model structures for the applied simulation of the anaerobic digestion of agricultural energy crops. BIORESOURCE TECHNOL. 2015;178:306-312.

17. Cirne DG, Paloumet X, Björnsson L, Alves MM, Mattiasson B. Anaerobic digestion of lipid-rich waste-effects of lipid concentration. RENEW ENERG. 2007;32:965-975.

18. Miron Y, Zeeman G, Van Lier JB, Lettinga G. The role of sludge retention time in the hydrolysis and acidification of lipids, carbohydrates and proteins during digestion of primary sludge in CSTR systems. WATER RES. 2000;34:1705-1713.

19. Kim JK, Oh BR, Chun YN, Kim SW. Effects of temperature and hydraulic retention time on anaerobic digestion of food waste. J BIOSCI BIOENG. 2006;102:328-332.

20. El-Mashad HM, Zhang R. Biogas production from co-digestion of dairy manure and food waste. BIORESOURCE TECHNOL. 2010;101:4021-4028.

21. Kim H, Han S, Shin $\mathrm{H}$. The optimisation of food waste addition as a co-substrate in anaerobic digestion of sewage sludge. WASTE MANAGE RES. 2003;21:515-526.

22. Donoso-Bravo A, Pérez-Elvira SI, Fdz-Polanco F. Application of simplified models for anaerobic biodegradability tests. Evaluation of pre-treatment processes. CHEM ENG J. 2010;160:607-614.

23. Li L, Kong X, Yang F, Li D, Yuan Z, Sun Y. Biogas production potential and kinetics of microwave and conventional thermal pretreatment of grass. APPL BIOCHEM BIOTECH. 2012;166:1183-1191.

24. Veeken A, Hamelers B. Effect of temperature on hydrolysis rates of selected biowaste components. BIORESOURCE TECHNOL. 1999;69:249-254. 
25. Wang X, Yang G, Li F, Feng Y, Ren G, Han X. Evaluation of two statistical methods for optimizing the feeding composition in anaerobic co-digestion: mixture design and central composite design. BIORESOURCE TECHNOL. 2013;131:172-178.

26. Pagliaccia P, Gallipoli A, Gianico A, Montecchio D, Braguglia CM. Single stage anaerobic bioconversion of food waste in mono and co-digestion with olive husks: Impact of thermal pretreatment on hydrogen and methane production. INT J HYDROGEN ENERG. 2016;41:905-915.

27. Pitt RE, Cross TL, Pell AN, Schofield P, Doane PH. Use of in vitro gas production models in ruminal kinetics. MATH BIOSCI. 1999;159:145-163.

28. Greenberg AE, Clesceri LS, Eaton AD. Standard methods for the examination of water and wastewater.: American Public Health Association; 1992.

29. Horwitz W. Official methods of analysis of association of official analytical chemists international: Association of Official Analytical Chemists International; 2000.

30. Jones Jr JB. Kjeldahl method for nitrogen determination. Kjeldahl method for nitrogen determination. 1991.

31. Thiex NJ, Anderson S, Gildemeister B. Crude fat, diethyl ether extraction, in feed, cereal grain, and forage (Randall/Soxtec/submersion method): collaborative study. J AOAC INT. 2003;86:888-898.

32. Angelidaki I, Sanders W. Assessment of the anaerobic biodegradability of macropollutants. Reviews in Environmental Science and Biotechnology. 2004;3:117-129.

33. Motulsky H, Christopoulos A. Fitting models to biological data using linear and nonlinear regression: a practical guide to curve fitting: OUP USA; 2004.

34. Chynoweth DP, Pullammanappallil P. Anaerobic digestion of municipal solid wastes. Microbiology of solid waste. 1996:71-113.

35. Zhang $\mathrm{C}, \mathrm{Su} \mathrm{H}$, Baeyens J, Tan T. Reviewing the anaerobic digestion of food waste for biogas production. Renewable and Sustainable Energy Reviews. 2014;38:383-392.

36. Braguglia CM, Gallipoli A, Gianico A, Pagliaccia P. Anaerobic bioconversion of food waste into energy: A critical review. BIORESOURCE TECHNOL. 2017;248:37-56.

37. Xu F, Li Y, Ge X, Yang L, Li Y. Anaerobic digestion of food waste - Challenges and opportunities. BIORESOURCE TECHNOL. 2018;247:1047-1058.

38. Zhou Q, Shen F, Yuan H, Zou D, Liu Y, Zhu B, et al. Minimizing asynchronism to improve the performances of anaerobic co-digestion of food waste and corn stover. BIORESOURCE TECHNOL. 2014;166:31-36.

39. Li Y, Zhang R, Liu G, Chen C, He Y, Liu X. Comparison of methane production potential, biodegradability, and kinetics of different organic substrates. BIORESOURCE TECHNOL. 2013;149:565-569.

40. Christ O, Wilderer PA, Angerhöfer R, Faulstich M. Mathematical modeling of the hydrolysis of anaerobic processes. WATER SCI TECHNOL. 2000;41:61-65.

41. Koch K, Helmreich B, Drewes JE. Co-digestion of food waste in municipal wastewater treatment plants: effect of different mixtures on methane yield and hydrolysis rate constant. APPL ENERG. 2015;137:250-255.

42. Bolzonella D, Fatone F, Pavan P, Cecchi F. Anaerobic fermentation of organic municipal solid wastes for the production of soluble organic compounds. IND ENG CHEM RES. 2005;44:3412-3418.

43. Eastman JA, Ferguson JF. Solubilization of particulate organic carbon during the acid phase of anaerobic digestion. Journal (Water Pollution Control Federation). 1981:352-366. 
44. Behera SK, Park JM, Kim KH, Park H. Methane production from food waste leachate in laboratory-scale simulated landfill. WASTE MANAGE. 2010;30:1502-1508.

45. Ramos C, Buitrón G, Moreno-Andrade I, Chamy R. Effect of the initial total solids concentration and initial $\mathrm{pH}$ on the bio-hydrogen production from cafeteria food waste. INT J HYDROGEN ENERG. 2012;37:13288-13295.

46. Wang J, Wan W. Kinetic models for fermentative hydrogen production: a review. INT J HYDROGEN ENERG. 2009;34:3313-3323.

47. Lü F, Zhou Q, Wu D, Wang T, Shao L, He P. Dewaterability of anaerobic digestate from food waste: Relationship with extracellular polymeric substances. CHEM ENG J. 2015;262:932-938.

48. Huiliñir C, Quintriqueo A, Antileo C, Montalvo S. Methane production from secondary paper and pulp sludge: effect of natural zeolite and modeling. CHEM ENG J. 2014;257:131-137.

49. Yang G, Zhang P, Zhang G, Wang Y, Yang A. Degradation properties of protein and carbohydrate during sludge anaerobic digestion. BIORESOURCE TECHNOL. 2015;192:126-130.

50. Naik SS, Setty YP. Optimization of parameters using response surface methodology and genetic algorithm for biological denitrification of wastewater. INT J ENVIRON SCI TE. 2014;11:823-830.

51. Li Y, Jin Y, Borrion A, Li H, Li J. Effects of organic composition on mesophilic anaerobic digestion of food waste. 2017;244:213-224.

52. Li Y, Jin Y, Borrion A, Li H, Li J. Effects of organic composition on the anaerobic biodegradability of food waste. BIORESOURCE TECHNOL. 2017;243:836-845. 